\title{
Long noncoding RNA MEG3 suppresses liver cancer cells growth through inhibiting $\beta$-catenin by activating PKM2 and inactivating PTEN
}

Qidi Zheng ${ }^{1}$, Zhuojia Lin ${ }^{1}$, Jie Xu' , Yanan Lu', Qiuyu Meng ${ }^{1}$, Chen Wang ${ }^{1}$, Yuxin Yang ${ }^{1}$, Xiaoru Xin ${ }^{1}$, Xiaonan Li ${ }^{1}$, $\mathrm{Hu} \mathrm{Pu}^{1}$, Xin Gui ${ }^{1}$, Tianming $\mathrm{Li}^{1}$, Wujun Xiong ${ }^{2}$ and Dongdong $\mathrm{Lu}^{1}$

\begin{abstract}
Maternally expressed gene 3 (MEG3) encodes an IncRNA which is suggested to function as a tumor suppressor and has been showed to involve in a variety of cancers. Herein, our findings demonstrate that MEG3 inhibits the malignant progression of liver cancer cells in vitro and in vivo. Mechanistically, MEG3 promotes the expression and maturition of miR122 which targets PKM2. Therefore, MEG3 decreases the expression and nuclear location of PKM2 dependent on miR122. Furthermore, MEG3 also inhibits CyclinD1 and C-Myc via PKM2 in liver cancer cells. On the other hand, MEG3 promotes $\beta$-catenin degradation through ubiquitin-proteasome system dependent on PTEN. Strikingly, MEG3 inhibits $\beta$-catenin activity through PKM2 reduction and PTEN increase. Significantly, we also found that excessive $\beta$-catenin abrogated the effect of MEG3 in liver cancer. In conclusion, our study for the first time demonstrates that MEG3 acts as a tumor suppressor by negatively regulating the activity of the PKM2 and $\beta$-catenin signaling pathway in hepatocarcinogenesis and could provide potential therapeutic targets for the treatment of liver cancer.
\end{abstract}

\section{Introduction}

Recent research has found that long noncoding RNAs (lncRNAs) were involved in various human cancers. Maternally expressed gene 3 (MEG3) has been shown to be involved in a variety of cancers and is downregulated in most cancers and affects cell proliferation, progression, and prognosis ${ }^{1-5}$. Notably, genetic variants and imprint change in MEG3 may contribute to the development and risk of cancer ${ }^{6,7}$. Moreover, MEG3 increases autophagy ${ }^{8}$, and epigenetic repression of MEG3 represses the p53 pathway and enhances $\mathrm{Wnt} / \beta$-catenin signaling ${ }^{9,10}$. In addition, MEG3 produces an antitumor effect in several

\footnotetext{
Correspondence: Dongdong Lu (ludongdong@tongji.edu.cn)

${ }^{1}$ Research Center for Translational Medicine at Shanghai East Hospital, School of Life Science and Technology, Tongji University, 200092 Shanghai, China 2Department of Hepatology, Shanghai East Hospital, Tongji University School of Medicine, 200120 Shanghai, China Edited by E. Candi
}

cancers $^{11,12}$. Furthermore, MEG3 functions as a competing endogenous RNA to regulate cancer progression ${ }^{13}$ and TGF- $\beta$ pathway genes through the formation of RNA-DNA triplex structures ${ }^{14}$. Strikingly, excessive MEG3 promotes osteogenic differentiation of mesenchymal stem cells from multiple myeloma patients by targeting BMP4 transcription ${ }^{15}$.

miR-122 is involved in human cancer proliferation, invasion, and progression ${ }^{16-19}$. In particular, miR-122 reverses the drug resistance and hepatotoxicity in hepatocellular carcinoma cells through regulating the tumor metabolism ${ }^{20,21}$. Pyruvate kinase muscle isozyme M2 (PKM2) is a limiting glycolytic enzyme that catalyzes the final step in glycolysis, which is key in tumor metabolism and growth ${ }^{22,23}$. Moreover, PKM2 plays a pivotal role in the growth, survival, and metabolic reprogramming of cancer cells ${ }^{24,25}$. Notably, loss of SIRT2 function in cancer cells reprograms their glycolytic metabolism via PKM2 
regulation ${ }^{26}$. In addition, our previous study indicates that double mutant P53 (N340Q/L344R) promotes hepatocarcinogenesis mediated by PKM 27 . Phosphatase and tensin homolog (PTEN) is one of the powerful switches for the conversion between tumor suppressors and oncogenes. A number of studies have suggested that PTEN may alter various functions of certain oncogenic proteins $^{28-33}$. Strikingly, PTEN opposes malignant transformation of pre-B cells and breast cells ${ }^{34,35}$. In particular, the PI3K-PTEN-AKT-mTOR pathway is a central controller of cell growth and a key driver for human cancer ${ }^{36}$. $\beta$-catenin (encoded by CTNNB1) is a subunit of the cell surface cadherin protein complex that acts as an intracellular signal transducer in the WNT signaling pathway. Many hepatic tumors such as hepatocellular adenomas, hepatocellular cancers, and hepatoblastomas have mutations in $\beta$-catenin that result in constitutive activation of $\beta$-catenin ${ }^{37}$. Also, Wnt $/ \beta$-catenin/TCF-4 signaling is crucial for the proliferation and self-renewal maintenance of cancer stem cells $^{38-41}$. Strikingly, MSK1-mediated $\beta$ catenin phosphorylation confers resistance to PI3K/ mTOR inhibitors in glioblastoma ${ }^{42}$.

In the present study, we indicate that MEG3 inhibits the malignant progression of liver cancer cells in vitro and in vivo. Our study for the first time demonstrated that MEG3 acts as a tumor suppressor by negatively regulating the activity of the PKM2 and $\beta$-catenin pathway in hepatocarcinogenesis and may provide potential therapeutic targets for the treatment of liver cancer.

\section{Experimental material and procedures Cell lines and plasmids}

Human liver cancer line Hep3B was maintained in DMEM medium supplemented with $10 \%$ heatinactivated fetal bovine serum (FBS) (Gibco) in a humidified atmosphere of $5 \% \mathrm{CO}_{2}$ incubator at $37^{\circ} \mathrm{C}$. Plasmids pGFP-V-RS, pCMV6-A-GFP, pCMV6-XL5- $\beta$ catenin, pCMV6-XL5-PTEN, pGFP-V-RS-PTEN, pGFPV-RS- $\beta$-catenin, and pMiR-Target were purchased from Origene (Rockville, MD 20850, USA). pEGP-miR122 (BioLab), pCMV6-A-GFP-MEG3 was constructed in our lab.

\section{Cell transfection and stable cell lines}

Cells were transfected with DNA plasmids using transfast transfection reagent lipofectamine ${ }^{\mathrm{R}} 2000$ (Invitrogen) according to manufacturer's instructions. For screening stable cell lines, $48 \mathrm{~h}$ after transfection, the cells were plated in the selective medium containing G418 (1000-2000 $\mu \mathrm{g} / \mathrm{ml}$, Invitrogen) or Puromycin $(1-2 \mu \mathrm{g} / \mathrm{ml}$, Calbiochem) for about 4 weeks or so, and the GFPpositive cells were selected and the selective media were replaced every 3 days.

\section{RT-PCR}

Total RNA was purified using Trizol (Invitrogen) according to manufacturer's instructions. cDNA was prepared by using oligonucleotide $(\mathrm{dT})_{17-18}$, random primers, and a SuperScript First-Strand Synthesis System (Invitrogen). The PCR reaction was performed in 36 cycles with each cycle consisting of a denaturation step $\left(94{ }^{\circ} \mathrm{C}\right.$ for $30 \mathrm{~s}$, and $3 \mathrm{~min}$ for the first cycle only), an annealing step $\left(56^{\circ} \mathrm{C}\right.$ (MEG3) or $55^{\circ} \mathrm{C}$ (PKM2 and $\beta$ actin) or $58^{\circ} \mathrm{C}$ (pre-miR122) for $30 \mathrm{~s}$ ), and an elongation step $\left(72^{\circ} \mathrm{C}\right.$ for $30 \mathrm{~s}, 10 \mathrm{~min}$ for the last cycle only). PCR primers: MEG3:P1: 5'-TCCATGCTGAGCTGCTGCCAAG-3'; P2: 5'- AGTCGACAAAGACTGACACCC-3'; PKM2P1: 5'-GCCACCATGTCGAAGCCCCATA-3'; P2: 5'-TCACGGCACAGGAACAACACGC-3'; pre-miR122: P1: 5'-TTGCCTAGCAGTAGCTATTT-3'; P2: 5' $^{\prime}$ GGCTACAGAGTTTCCTTAGC- ${ }^{\prime}$. $\beta$-actin was used as an internal control.

\section{MicroRNA detection}

Total RNA was isolated from cultured cells using Trizol (Invitrogen, Carlsbad, CA, USA) according to the manufacturer's protocol. Real-time RT-PCR-based detection of mature miR-122 and U6 snRNA was achieved with the miRNA Detection kit (including a universal primer, U6 primers, Qiagen) and miR122 specific upstream primers (mature miR122:P1: 5'-TGGAGTGTGACAATGGTGTTTG-3' Origene, USA). qRT-PCR was performed with a StepOne Plus real-time PCR system (Applied Biosystems). The real-time PCR reaction was performed in 40 cycles with each cycle consisting of a denaturation step $\left(95^{\circ} \mathrm{C}\right.$ for $15 \mathrm{~s}$, and $15 \mathrm{~min}$ for the first cycle only) and an annealing step $\left(60^{\circ} \mathrm{C}\right.$ for $\left.30 \mathrm{~s}\right)$. Each sample was run in triplicate. $C_{\mathrm{t}}$ values for miR122 were calculated and normalized to $C_{\mathrm{t}}$ values for U6 snRNA.

\section{Western blotting}

The logarithmically growing cells were washed twice with ice-cold phosphate-buffered saline (PBS, Hyclone) and lysed in a RIPA lysis buffer. Cells lysates were centrifuged at $12,000 \mathrm{~g}$ for $20 \mathrm{~min}$ at $4{ }^{\circ} \mathrm{C}$ after sonication on ice, and the supernatant was separated. After being boiled for 5-10 $\mathrm{min}$ in the presence of 2-mercaptoethanol, the samples containing cellulars proteins were separated on a $10 \%$ sodium dodecyl sulfate-polyacrylamide gel electrophoresis (SDS-PAGE) and transferred onto a nitrocellulose membrane, blocked in 10\% dry milk-TBST (20 mM Tris- $\mathrm{HCl}$ (pH 7.6), $127 \mathrm{mM} \mathrm{NaCl}, 0.1 \%$ Tween 20) for $1 \mathrm{~h}$ at $37^{\circ} \mathrm{C}$. Following three washes in Tris- $\mathrm{HCl} \mathrm{pH} 7.5$ with $0.1 \%$ Tween 20 , the blots were incubated with $0.2 \mu \mathrm{g} / \mathrm{ml}$ of antibody (appropriate dilution) overnight at $4{ }^{\circ} \mathrm{C}$. Following three washes, the membranes were then incubated with secondary antibody for $60 \mathrm{~min}$ at $37^{\circ} \mathrm{C}$ or $4{ }^{\circ} \mathrm{C}$ overnight in TBST. Signals were visualized by ODYSSEY 
infrared imaging system (LI-COR, Lincoln, Nebraska, USA). IRDye 680LT/IRDye $800 \mathrm{CW}$ secondary antibodies $(1: 50,000)$ were purchased from LI-COR Scientific Company. Standard Western blotting procedures were used with the following antibodies: anti-PCNA (Santa Cruz, Biotech), anti-CTCF (Santa Cruz, Biotech), anti-CREB (Santa Cruz, Biotech), anti-RNA polII(Abcam), antiH3K9me3 (Abcam), anti-H3K36me3 (Abcam), antiPKM2 (Abcam), anti-ERK1/2 (Abcam), anti-pPKM2 (ser37) (Cell signaling), anti-Histone H3 (Abcam), antiH3K9Ac (Abcam), anti-METTL3 (Santa Cruz, Biotech), anti-AKT (Abcam), anti-pAKT (Abcam), anti-GSK3 $\beta$ (ser9), anti-GSK3 $\beta$ (Tyr216), anti-GSK3 $\beta$ (Santa Cruz, Biotech), anti- $\beta$-catenin (Santa Cruz, Biotech), anti-HA, anti-Skp2 (Santa Cruz, Biotech), anti-TCF4 (Santa Cruz,
Biotech), anti-LEF (Santa Cruz, Biotech), anti-PTEN (Santa Cruz, Biotech), anti-LEF (Santa Cruz, Biotech), anti-TCF4 (Santa Cruz, Biotech), anti-C-myc (Santa Cruz, Biotech), and anti-cyclinD1 (Santa Cruz, Biotech).

\section{Co-immunoprecipitation (IP)}

Cells were lysed in $1 \mathrm{ml}$ of whole-cell extract buffer A (50 mM pH 7.6 Tris-HCl, $150 \mathrm{mM} \mathrm{NaCl}, 1 \%$ NP40, 0.1 mM EDTA, $1.0 \mathrm{mM}$ DTT, $0.2 \mathrm{mM}$ PMSF, $0.1 \mathrm{mM}$ Pepstatine, $0.1 \mathrm{mM}$ Leupeptine, $0.1 \mathrm{mM}$ Aproine); $500 \mu \mathrm{l}$ cell lysates were used for IP with antibody. In brief, protein was pre-cleared with $30 \mu \mathrm{l}$ protein G/A-plus agarose beads (Santa Cruz, Biotechnology, Inc., CA) for $1 \mathrm{~h}$ at $4{ }^{\circ} \mathrm{C}$ and the supernatant was obtained after centrifugation (5000 rpm) at $4{ }^{\circ} \mathrm{C}$. Pre-cleared homogenates

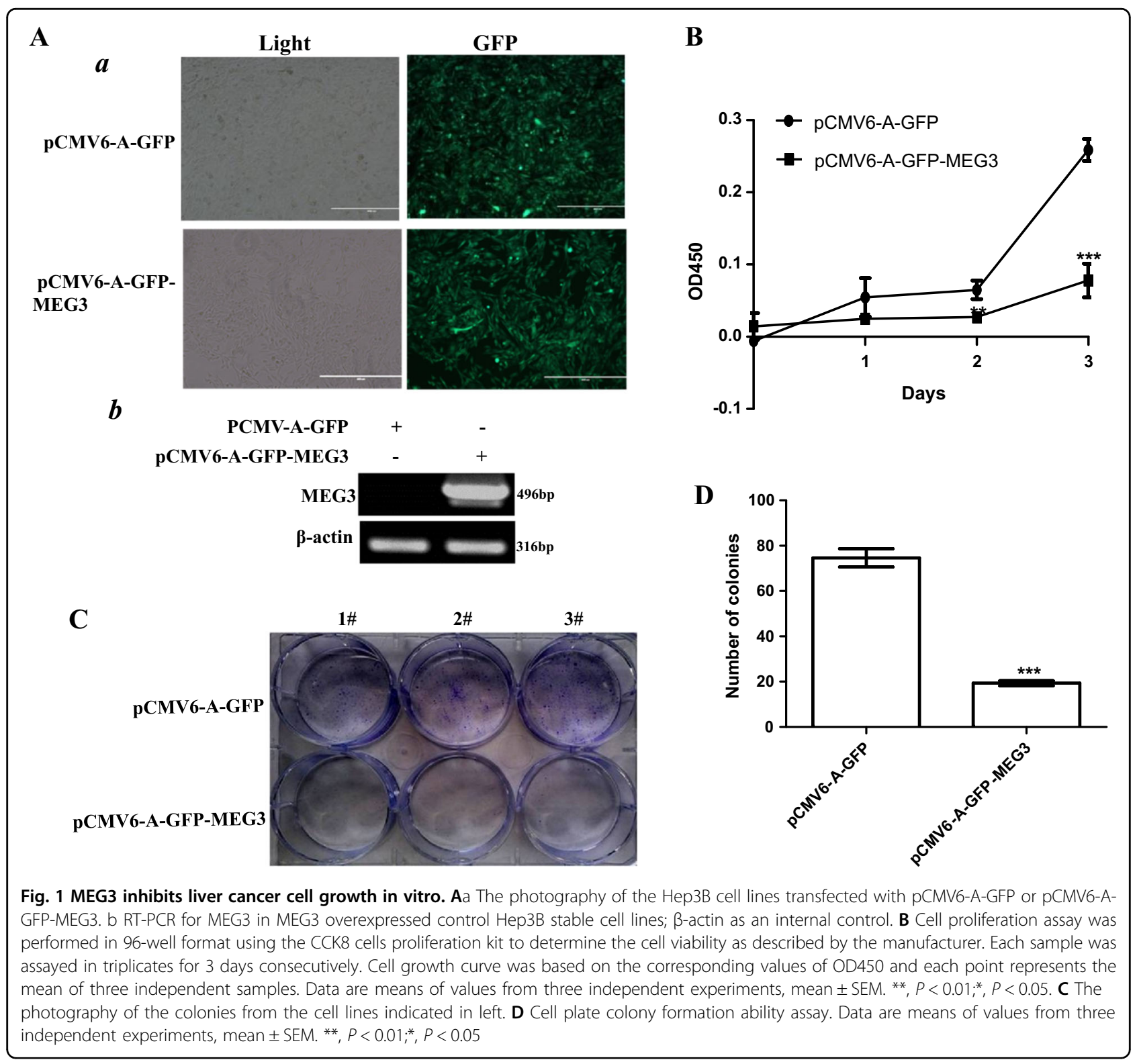




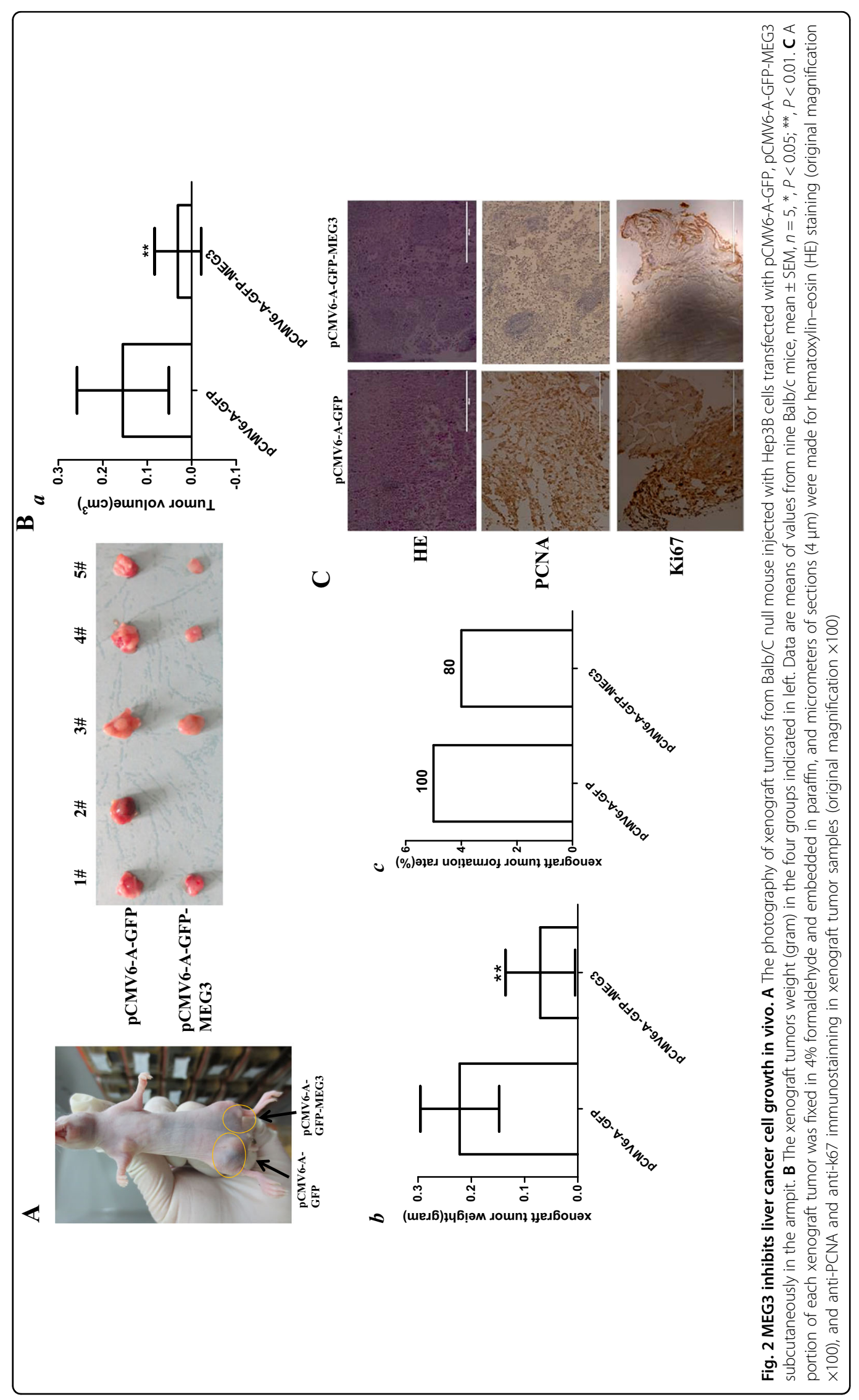




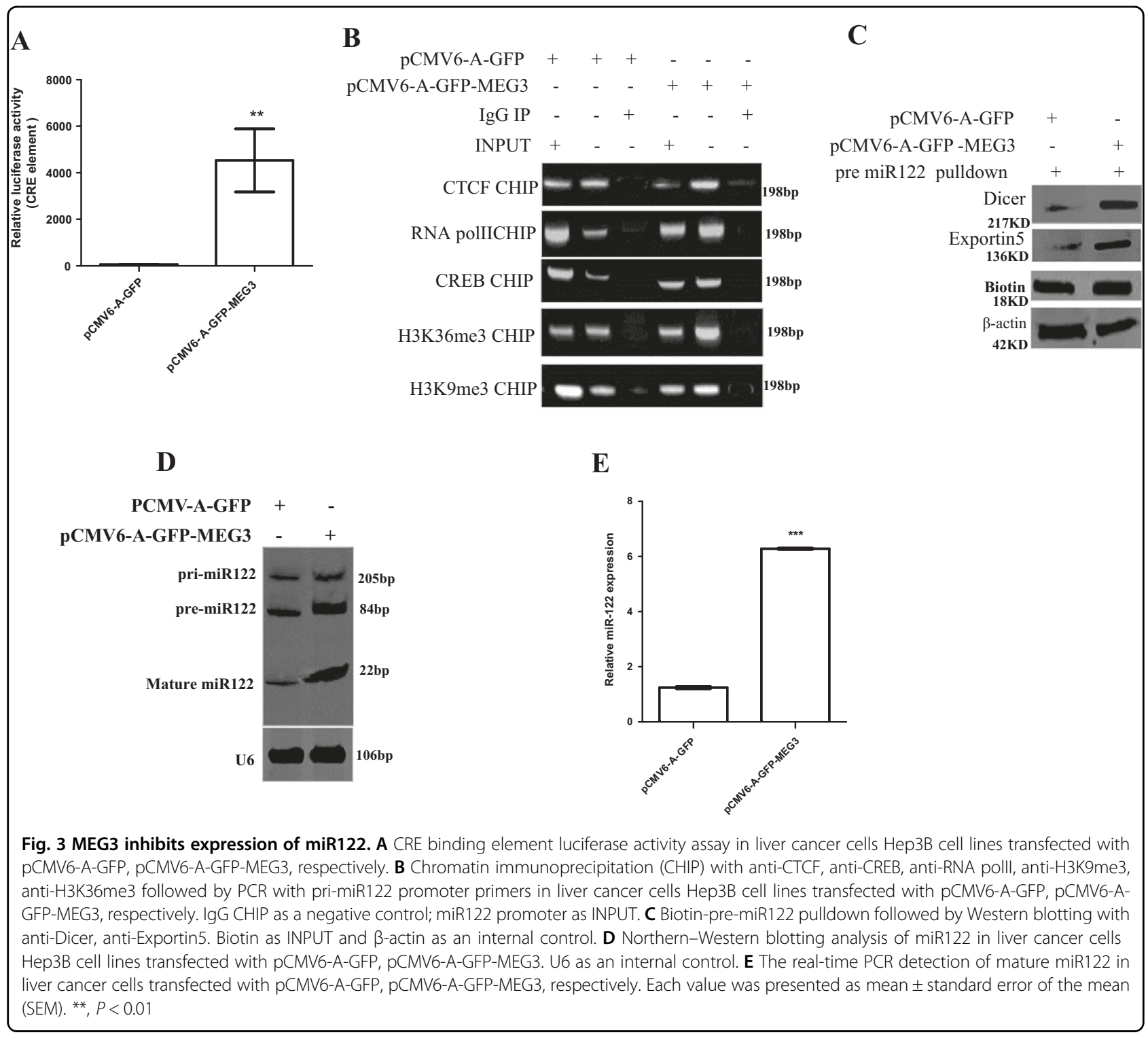

(supernatant) were incubated with $2 \mu \mathrm{g}$ of antibody and/or normal mouse/rabbit IgG with rotation for $4 \mathrm{~h}$ at $4{ }^{\circ} \mathrm{C}$. The immunoprecipitates were incubated with $30 \mu$ protein G/A-plus agarose beads by rotation overnight at $4{ }^{\circ} \mathrm{C}$, and then centrifuged at $5000 \mathrm{rpm}$ for $5 \mathrm{~min}$ at $4{ }^{\circ} \mathrm{C}$. The precipitates were washed five times for $10 \mathrm{~min}$ with beads wash solution $(50 \mathrm{mM}$ pH 7.6 Tris- $\mathrm{HCl}, 150 \mathrm{mM} \mathrm{NaCl}$, $0.1 \%$ NP-40, 1 mM EDTA), resuspended in $60 \mu \mathrm{l} 2 \times$ SDSPAGE sample loading buffer, and incubated for 5-10 min at $100{ }^{\circ} \mathrm{C}$. Western blotting was performed with related antibodies.

\section{RNA immunoprecipitation (RIP)}

Cells were lysed $\left(15 \mathrm{~min}, 0^{\circ} \mathrm{C}\right)$ in $100 \mathrm{mM} \mathrm{KCl}, 5 \mathrm{mM}$ $\mathrm{MgCl}_{2}, 10 \mathrm{mM}$ HEPES [pH 7.0], 0.5\% NP40, 1 mM DTT, 100 units/ml RNase OUT (Invitrogen), $400 \mu \mathrm{M}$ vanadyl-ribonucleoside complex, and protease inhibitors (Roche), clarified and stored at $-80^{\circ} \mathrm{C}$. Ribonucleoprotein particle-enriched lysates were incubated with protein $\mathrm{A} /$ G-plus agarose beads (Santa Cruz, Biotechnology, Inc., CA) together with the antibody or normal mouse or rabbit IgG for $4 \mathrm{~h}$ at $4{ }^{\circ} \mathrm{C}$. Beads were subsequently washed four times with $50 \mathrm{mM}$ Tris- $\mathrm{HCl}(\mathrm{pH} 7.0), 150$ $\mathrm{mM} \mathrm{NaCl}, 1 \mathrm{mM} \mathrm{MgCl}$, and $0.05 \% \mathrm{NP}-40$, and twice after addition of $1 \mathrm{M}$ urea. Immunoprecipitates were digested with proteinase $\mathrm{K}\left(55^{\circ} \mathrm{C} ; 30^{\prime}\right)$ and mRNAs were isolated and purified, and then RT-PCR was performed.

\section{Super-EMSA (gel-shift)}

Cells were washed and scraped in ice-cold PBS to prepare nuclei for electrophoretic gel mobility shift assay with the use of the gel shift assay system modified 


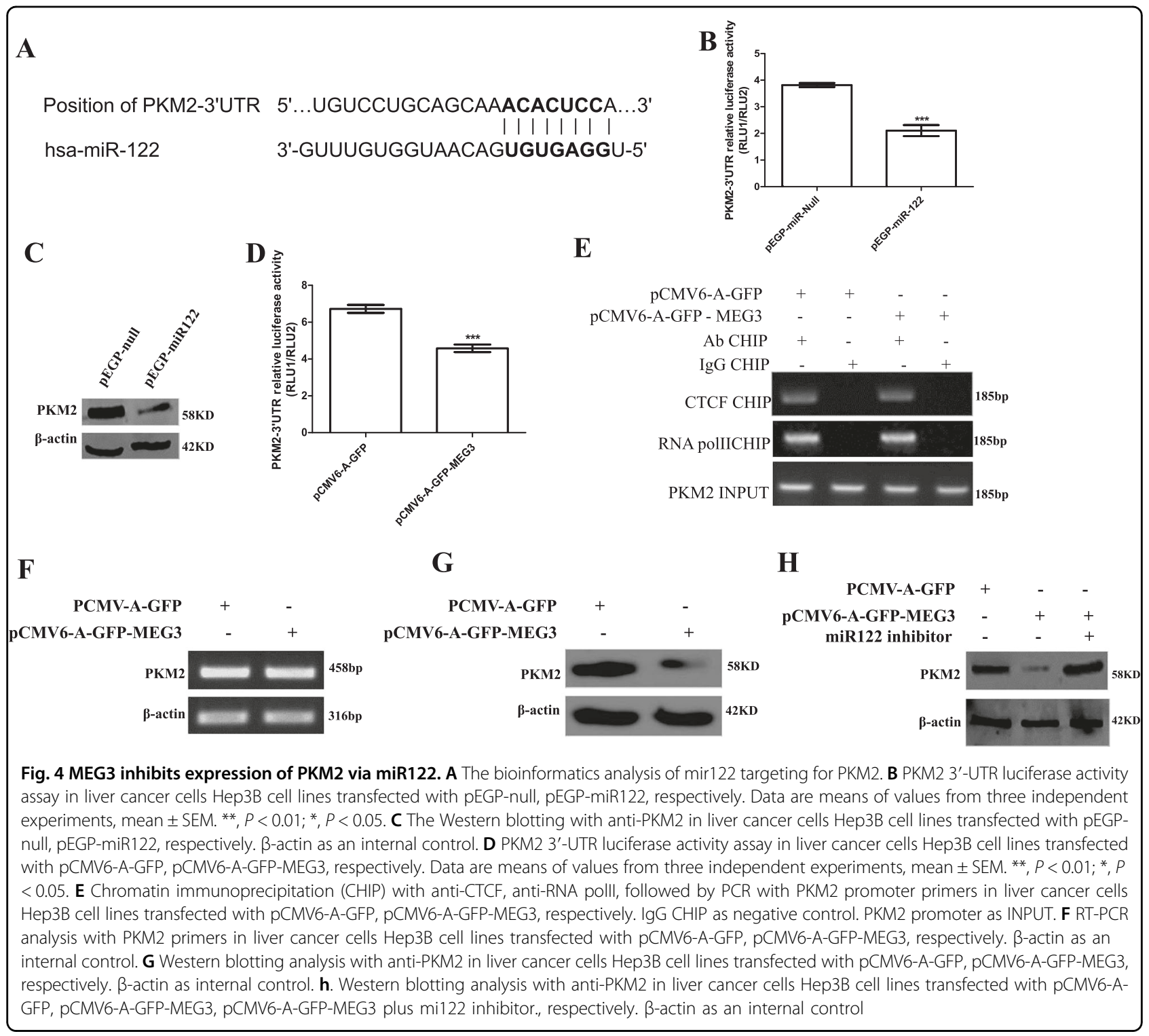

according to the manufacturer's instructions (Promega). In brief, consensus oligonucleotides for damage or repair DNA were biotin-labeled (hot probe). Each binding reaction was carried out with $1 \mu \mathrm{g}$ biotinylated dsDNA probe and $200 \mu \mathrm{g}$ purified nuclear protein in $20 \mu \mathrm{l}$ of binding buffer containing $0.5 \mathrm{mg} / \mathrm{ml}$ poly $(\mathrm{dI}: \mathrm{dC})(25 \mathrm{mM}$ HEPES at pH 8.0 with $50 \mathrm{mM} \mathrm{KCl}, 0.1 \%$ Triton X100, 2 $\mathrm{mM} \mathrm{MgCl} 2,3 \mathrm{mM} \mathrm{DTT}$, and 5\% glycerol). Twenty-five pmol unlabeled cold DNA motifs (a 250-fold excess) were added in the competition assays. Reactions were carried out for $30 \mathrm{~min}$ incubation at room temperature, followed by overnight incubation at $4{ }^{\circ} \mathrm{C}$. Reaction mixtures were loaded onto $6 \% \mathrm{TBE}$ polyacrylamide gels and separated in $0.5 \% \times \mathrm{TBE}$ at $100 \mathrm{v}$ on ice until the dye front migrated two-thirds of the way to $\mathrm{NC}$ membranes and Western blotting was performed for anti-biotin.

\section{Dual luciferase reporter assay}

Cells were transfected with luciferase construct plasmids and pRL-tk. After incubation for $48 \mathrm{~h}$, the cells were harvested with Passive Lysis Buffer (Promega), and luciferase activities of cell extracts were measured with the use of the Dual luciferase assay system (Promega) according to manufacturer's instructions. Luciferase activity was measured and normalized for transfection efficiency with Renilla luciferase activity.

\section{Chromatin immunoprecipitation (CHIP)}

Cells were cross-linked with $1 \%(\mathrm{v} / \mathrm{v})$ formaldehyde for $10 \mathrm{~min}$ at room temperature and stopped with $125 \mathrm{mM}$ glycine for $5 \mathrm{~min}$. Cross-linked cells were washed with PBS, resuspended in lysis buffer, and sonicated for 8-10 $\mathrm{min}$ in a SONICS. Chromatin extracts were pre-cleared 
with Protein-A/G-Sepharose beads, and immunoprecipitated with specific antibody on Protein-A/G-Sepharose beads. After washing, elution, and de-cross-linking, the ChIP DNA was detected by PCR. The following primer pairs were used: C-myc CHIP promoter: P1: 5'TAACTCGCTGTAGTAATTCC-3'; P2: 5 'CCCTATGGGCAAAGTTTCGT-3'; CyclinD1 CHIP promoter: P1: 5'-GAAGAGTCTCCAGGCTAGAA-3'; P2: 5'-TTGTAGCCTGGAGACTCTTC-3'.

\section{Cells proliferation CCK8 assay}

Cells were synchronized in G0 phase by serum deprivation and then released from growth arrest by re-exposure to serum, and then cells were grown in complete medium for assay. The cell proliferation reagent CCK8 was purchased from Roch and the operation was carried out according to the manufacturer's instruction. In brief, cells at a concentration $4 \times 10^{3}$ were seeded into 96-well culture plates in $100 \mu \mathrm{l}$ culture medium containing $10 \%$ heat-inactivated fetal calf serum (FCS). Before detection, $10 \mu \mathrm{g} /$ well cell proliferation reagent CCK8 was added and incubated for 4 $\mathrm{h}$ at $37^{\circ} \mathrm{C}$ and $5 \% \mathrm{CO}_{2}$. Cell growth curve was based on the corresponding normalized values of OD450 and each point represents the mean of three independent samples.

\section{Colony-formation efficiency assay}

$5 \times 10^{2}$ cells were plated on a $10-\mathrm{cm}$ dish, then $10 \mathrm{ml}$ DMEM containing $10 \%$ FBS was added into each $10-\mathrm{cm}$ dish of the three replicates. Then these dishes were incubated at $37^{\circ} \mathrm{C}$ in a humidified incubator for 10 days. The cell colonies on the dishes were stained with $1 \mathrm{ml}$ of $0.5 \%$ Crystal Violet for more than $1 \mathrm{~h}$ and the colonies were counted.

\section{Xenograft transplantation in vivo}

Four-weeks-old male athymic Balb/C mice were purchased from Shi Laike Company (Shanghi, China) and maintained in the Tongji animal facilities approved by the China Association for Accreditation of Laboratory Animal Care. The athymic Balb/C mice were injected in the armpit area subcutaneously with Hep3B suspension of $1 \times 10^{6}$ cells in $100 \mu \mathrm{l}$ of PBS. The mice were observed over 4 weeks, and then sacrificed to recover the tumors. The wet weight of each tumor was determined for each mouse. A portion of each tumor was fixed in $4 \%$ paraformaldehyde and embedded in paraffin for histological hematoxylin-eosin (HE) staining.

\section{Ethics statement}

All methods were carried out in "accordance" with the approved guidelines. All experimental protocols "were approved by" a Tongji university institutional committee. Informed consent was obtained from all subjects. The use of mice was reviewed and approved by the China national institutional animal care and use committee".

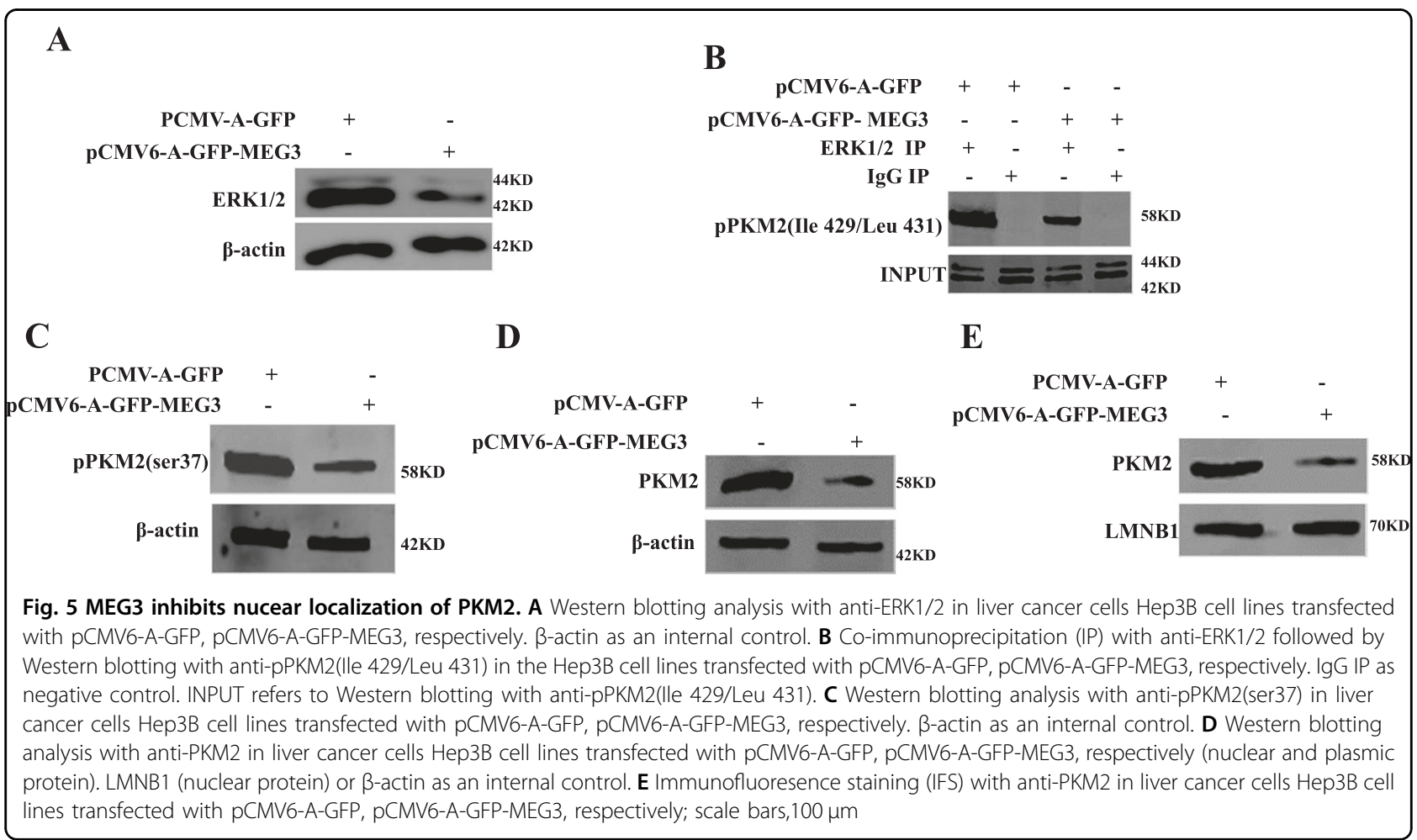




\section{Results}

MEG3 inhibits liver cancer cell growth in vitro and in vivo

To investigate whether MEG3 inhibited the malignant growth of human liver cancer cell line Hep3B, we first established two stable Hep3B cell lines transfectd with pCMV6-A-GFP (GFP ctrl), pCMV6-A-GFP-MEG3 (MEG3), respectively. As shown in Fig. 1a, the expression of MEG3 was significantly increased in MEG3 overexpressing Hep3B on the transcriptional level. As shown in Fig. 1b, excessive MEG3 significantly decreased the growth of liver cancer cell Hep3B compared to the control cells $(P<0.01)$. We further performed plate colony formation assay and observed a significant decrease in colony formation efficiency rate in excessive MEG3 $(74.67 \pm 4.04$ versus $19.33 \pm 1.15, P=1.0957 \mathrm{E}-05<0.01)$ (Fig. 1c, d). To explore the effect of MEG3 on liver cancer cells in vivo, the two stable Hep3B were injected subcutaneously into athymic Balb/C mice. As shown in Fig. 2a-c, when MEG3 was overexpressed, the xenograft tumor weight decreased approximately one-third compared to the corresponding control group $(0.22152 \pm$ $0.07382 \mathrm{~g}$ versus $0.07042 \pm 0.0652 \mathrm{~g}, \quad P=0.004061372$
$<0.01$ ); when MEG3 was overexpressed, the xenograft tumor size decreased approximately one-fifth compared to the corresponding control group $\left(0.15508 \pm 0.1035 \mathrm{~cm}^{3}\right.$ versus $\left.0.03125 \pm 0.05229 \mathrm{~cm}^{3}, \quad P=0.007228<0.01\right)$. Moreover, compared to control, xenograft tumors contained less of poorly differentiated cells in MEG3 overexpression group (Fig. 2d, upper). The proliferation index (calculated as percentage of PCNA-positive cells) and Ki67 were significantly lower in MEG3 overexpressing xenograft tumors compared to the control group (Fig. 2d, middle and lower). Taken together, these findings demonstrate that MEG3 inhibits malignant progression of liver cancer cells in vitro and in vivo.

\section{MEG3 promotes the expression and mature of miR122} which targets for PKM2 and inhibits expression of PKM2

To address whether MEG3 influences the expression and maturation of miR122, we performed related experiments in MEG3 or miR122 overexpressing Hep3B cell line. As shown in Fig. 3a, MEG3 could enhance the CRE luciferase activity in Hep3B cells. Moreover, MEG3 overexpression enhanced the loading of CTCF, CREB,

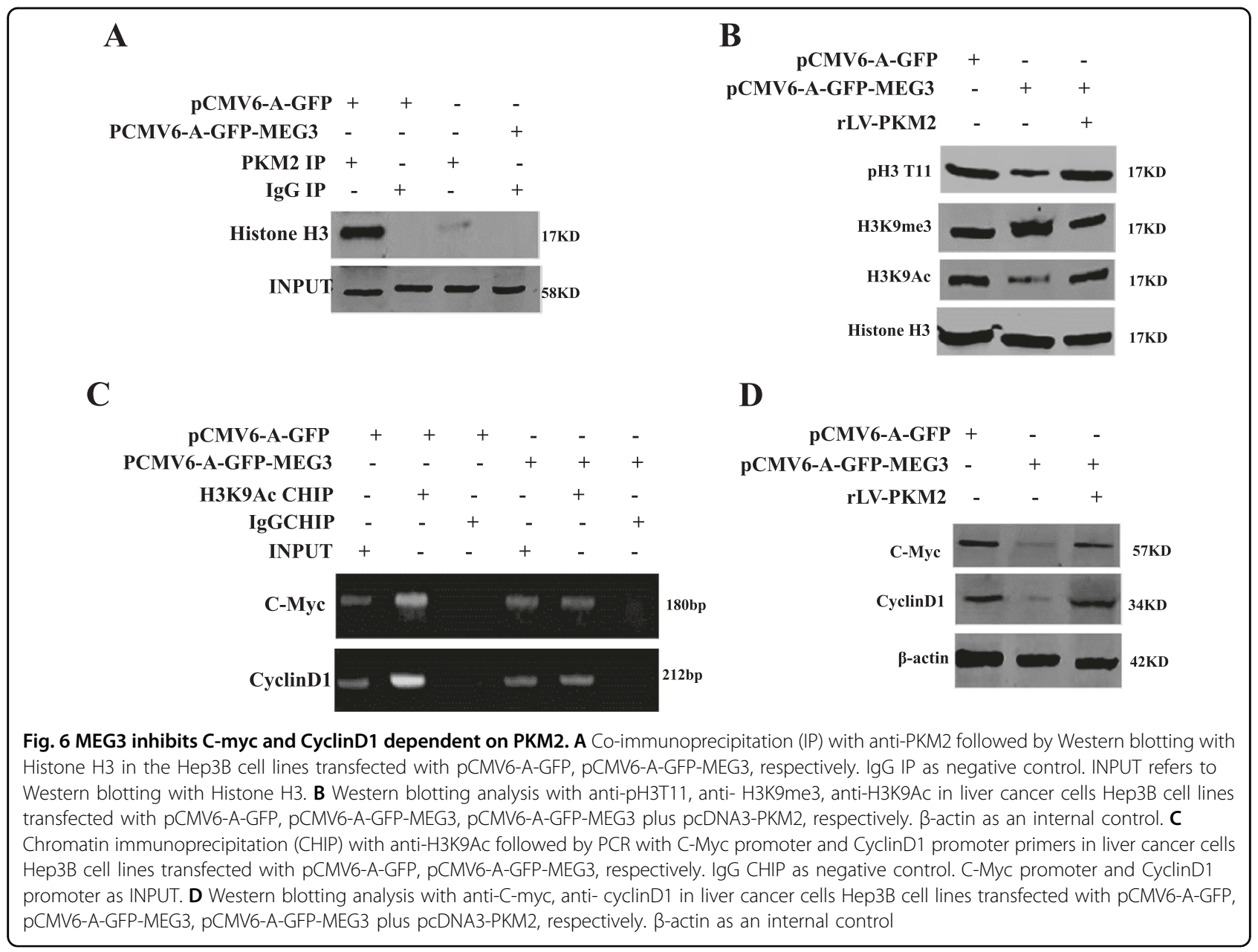


H3K9me3, H3K36me3, RNA pollI on the miR122 promoter region (Fig. 3b). Furthermore, MEG3 overexpression enhanced the binding of Dicer, Exportin 5 to the pre-miR122 probe (Fig. 3c). Importantly, the peimiR122, pre-miR122, and mature miR122 were significantly increased in excessive MEG3 group compared to the control group (Fig. 3d, e). Surprisingly, miR122 targets for $3^{\prime}$-untranslational region (UTR) of PKM2 (Fig. 4a), and inhibits PKM2 3-UTR luciferase activity (Fig. 4b) and PKM2 expression (Fig. 4c). Taken together, MEG3 promotes the expression and maturation of miR122 which targets PKM2 and inhibits the expression of PKM2.

\section{MEG3 inhibits localization and function of PKM2}

To explore whether MEG3 could influence the function of PKM2, we selected PKM2-upregulated C-Myc and CyclinD1. At first, the results showed that PKM2 3'-UTR luciferase activity was significantly decreased in pCMV6A-GFP-MEG3 group compared to the control group $(P<$
0.01) (Fig. 4d). Furthermore, MEG3 could not significantly alter the loading of CTCF and RNA polII on the promoter region of PKM2 (Fig. 4e). Thus, the PKM2 mRNA was significantly unchanged in pCMV6-A-GFP-MEG3 group compared to the control group (Fig. 4f). Significantly, the PKM2 expression was significantly decreased in pCMV6A-GFP-MEG3 group compared to the control group (Fig. 4g). However, when the miR122 was inhibited, the PKM2 expression was significantly unaltered in pCMV6A-GFP-MEG3 group compared to the control group (Fig. 4h). Moreover, MEG3 could reduce the ERK1/2 expression (Fig. 5a) and the interplay between ERK1/2 and pPKM2(Ile 429/Leu 431) (Fig. 5b). Therefore, The PKM2(ser37) expression was significantly decreased in pCMV6-A-GFP-MEG3 group compared to the control group (Fig. 5c). Furthermore, the nuclear PKM2 was significantly reduced in pCMV6-A-GFP-MEG3 group compared to the control group (Fig. 5d, e). Strikingly, the interaction between PKM2 and Histone $\mathrm{H} 3$ was significantly decreased in pCMV6-A-GFP-MEG3 group

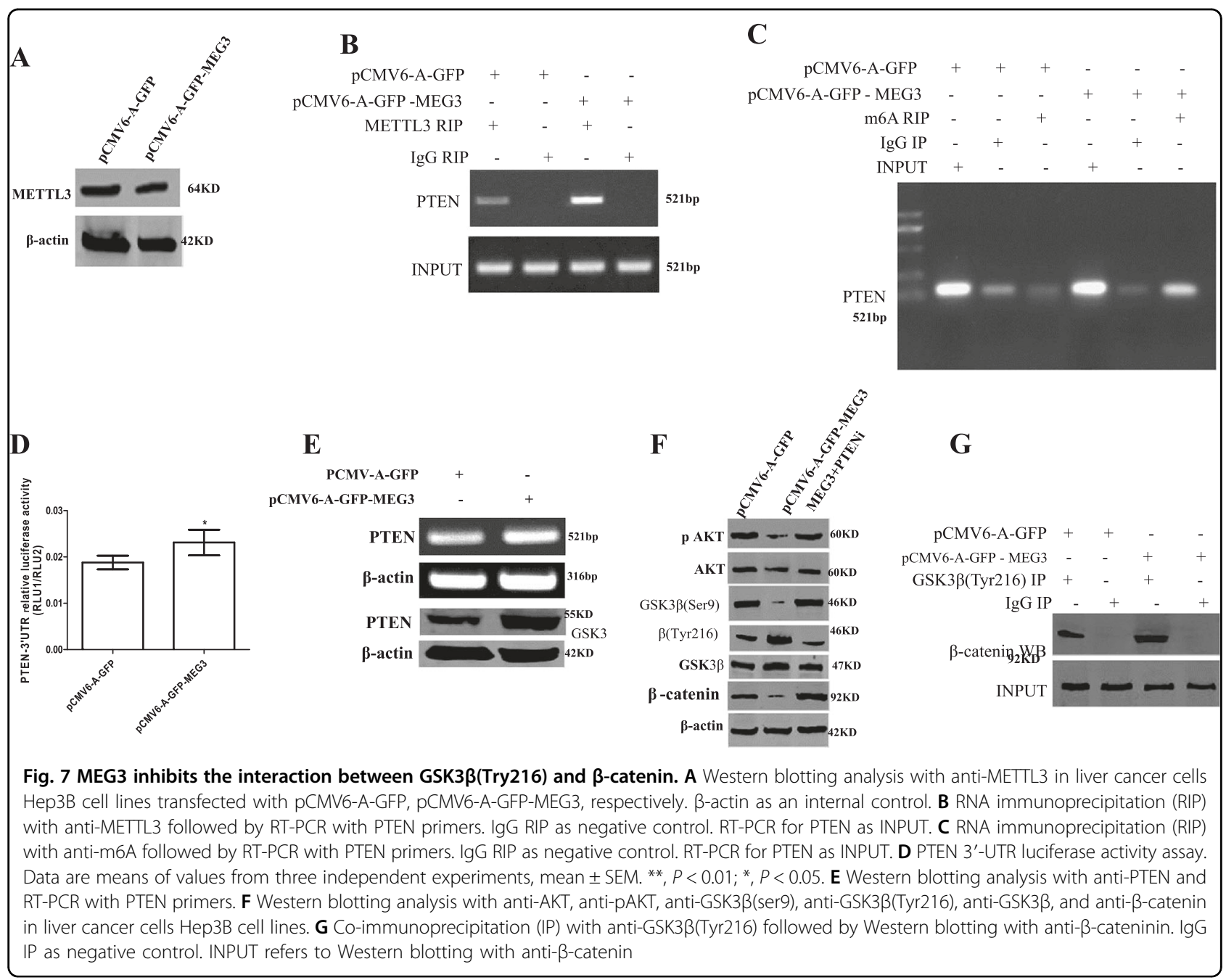




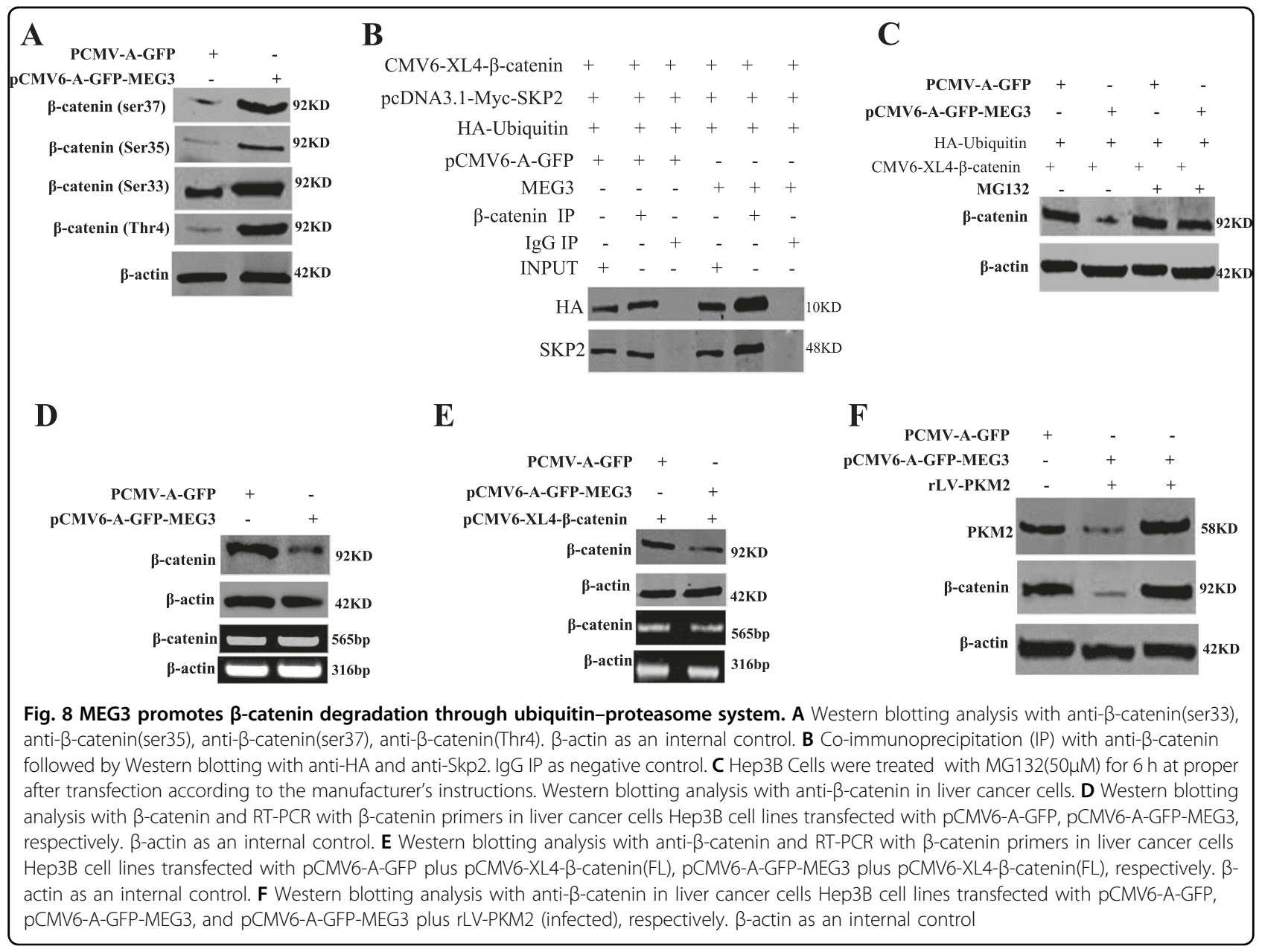

compared to the control group (Fig. 6a). Thus, MEG3 decreased pHiatone H3(T11), H3K9Ac, and increased H3K9me3. However, PKM2 knockdown abrogated the MEG3 action (Fig. 6b). Furthermore, MEG3 decreased the loading of H3K9Ac on CyclinD1 and C-Myc promoter region (Fig. 6c). Ultimately MEG3 decreased the expression of CyclinD1 and C-Myc. However, the expression of CyclinD1 and C-Myc did not alter in Hep3B cell line with MEG3 overexpression plus PKM2 knockdown (Fig. 6d). Taken together, these observations suggest that MEG3 decreased the PKM2 expression and nuclear location dependent on miR122, and then inhibited CyclinD1 and $\mathrm{C}-\mathrm{Myc}$ via PKM2.

\section{MEG3 promotes $\beta$-catenin degradation through ubiquitin-proteasome system dependent on PTEN}

Given MEG3 could inhibit hepatocarcinogenesis, we consider to address whether MEG3 could regulate oncogenes, e.g., $\beta$-catenin. At first, we investigated whether MEG3 could alter the expression of PTEN. Although MEG3 did not influence the expression of METTL3 (a enzyme of mRNA methylation) (Fig. 7a), however, MEG3 overexpression increased the interaction between METTL3 and PTEN 3-UTR (Fig. 7b). Therefore, MEG3 overexpression increased the PTEN 3-UTR mRNA methylation compared to control (Fig. 7c). Furthermore, MEG3 overexpression increased the PTEN 3-UTR luciferase activity compared to control $(P<0.01)$ (Fig. $7 d$ ). The expression of PTEN was significantly increased on the transcriptioanal and translational level in MEG3 overexpressing group compared to control (Fig. 7e). Therefore, excessive MEG3 overexpression decreased the expression of pAKT, GSK3 $\beta($ Ser9), $\beta$-catenin, and increased the expression of GSK3 $\beta$ (Tyr216). However, PTEN overexpression abrogated the MEG3 action (Fig. 7f). Interestingly, MEG3 overexpression increased the interaction between GSK3 $\beta$ (Tyr216) and $\beta$-catenin (Fig. 7g). Thus, excessive MEG3 increased the expression and modification of $\beta$-catenin (ser33, ser35, ser37, and Thr4) (Fig. 8a). Furthermore, MEG3 overexpression increased the interaction between $\beta$-catenin and HA-Ub, Skp2 (Fig. 8b). Strikingly, MEG3 overexpression increased the degradation of $\beta$-catenin. In particular, MEG132 abrogated the MEG3 action (Fig. 8c). Ultimately, 


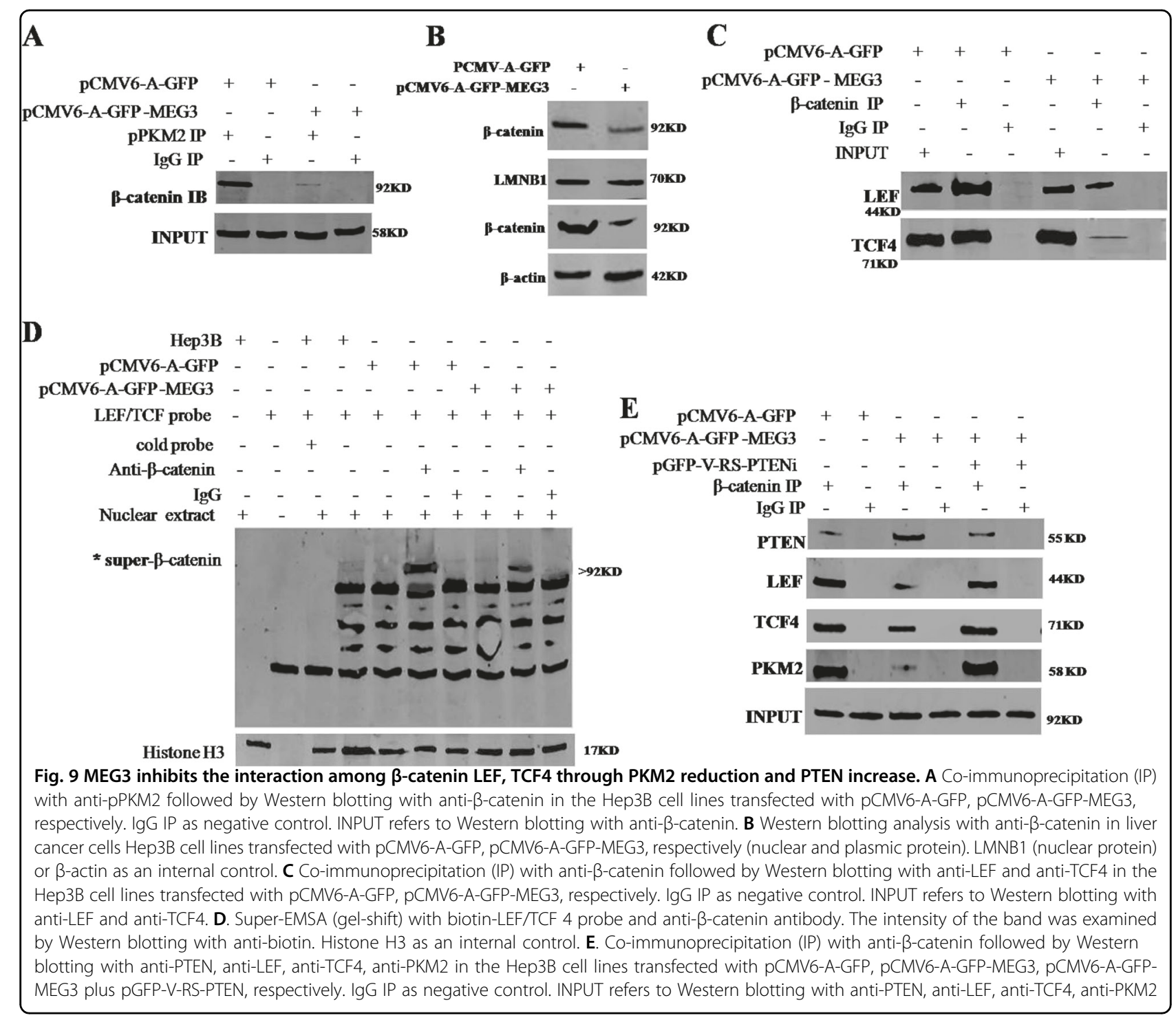

excessive MEG3 decreased the expression of $\beta$-catenin. However, MEG3 overexpression could not alter the transcription of $\beta$-catenin (Fig. 8d, e). Excessive PKM2 could rescue MEG3-mediated $\beta$-catenin degradation (Fig. 8f). Taken together, these observations suggest that MEG3 increases the degradation of $\beta$-catenin through ubiquitin-proteasome system dependent on PTEN.

\section{MEG3 inhibits $\beta$-catenin activity through PKM2 reduction and PTEN increase}

To explore whether MEG3 influenced $\beta$-catenin activity, we analyzed the activity of $\beta$-catenin co-activators LEF and TCF-4 in liver cancer cells. As shown in Fig. 9a, MEG3 overexpression decreased the interaction between pPKM2 and $\beta$-catenin. Thereby, MEG3 overexpression decreased the expression and nuclear localization of $\beta$ catenin (Fig. 9b). Furthermore, MEG3 overexpression decreased the interaction between $\beta$-catenin and LEF, TCF4 in liver cancer cells. (Fig. 9c). Therefore, MEG3 overexpression decreased the binding of $\beta$-catenin to LEF/ TCF4 probe (Fig. 9d). In particular, MEG3 overexpression increased the interplay between $\beta$-catenin and PTEN, and decreased the interplay between $\beta$-catenin and LEF, TCF4. However, the MEG3 action was abrogated when the PTEN was knocked down (Fig. 9e). MEG3 overexpression decreased the activity of LEF/TCF4 (Fig. 10a). Furthermore, MEG3 overexpression decreased the loading of Cmyc promoter region and CyclinD1 promoter region (Fig. 10b). Thereby, MEG3 overexpression decreased the promoter luciferase of C-myc (Fig. 10c) and CyclinD1 (Fig. 10d). However, the MEG3 action was abrogated when the $\beta$-catenin was knocked down (Fig. 10c, d). Finally, MEG3 overexpression decreased the expression of C-myc and CyclinD1 on the level of transcription and 


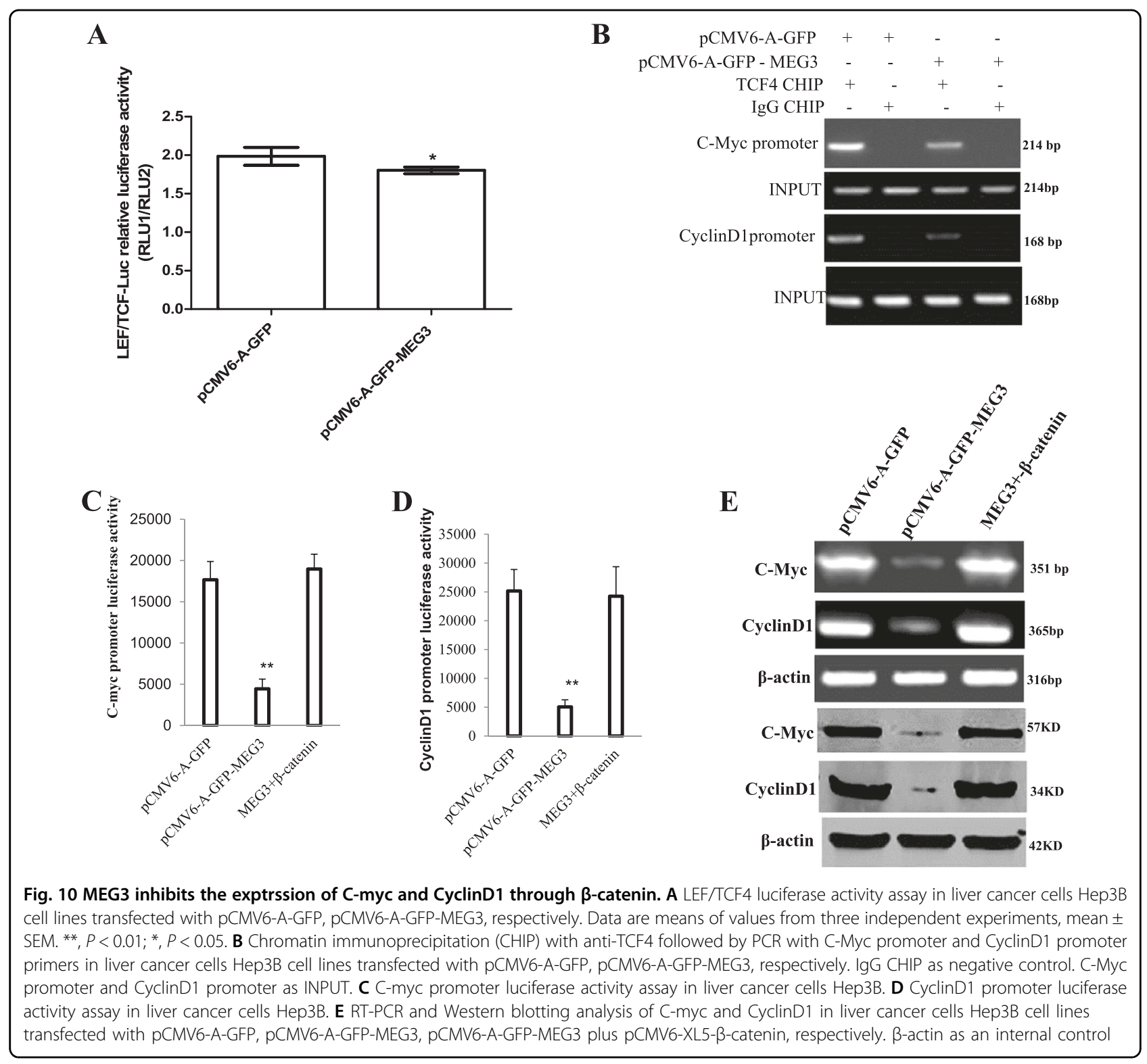

translation. However, the MEG3 action was abrogated when $\beta$-catenin was knocked down (Fig. 10e). Collectively, these observations suggest that MEG3 inhibits $\beta$-catenin activity through PKM2 reduction and PTEN increase in liver cancer cells.

\section{$\beta$-catenin determines the functions of MEG3 suppressor}

To explore whether MEG3 suppressor function is associated with $\beta$-catenin, we established three stable Hep3B cell lines (pCMV6-A-GFP, pCMV6-A-GFPMEG3, pCMV6-A-GFP-MEG3 plus pCMV6-XL4- $\beta$ catenin). As shown in Fig. 11a, compared to control, MEG3 was overexpressed in stable Hep3B cell lines transfected with pCMV6-A-GFP-MEG3, pCMV6-A-GFPMEG3 plus pCMV6-XL4- $\beta$-catenin, and $\beta$-catenin was overexpressed in stable Hep3B cell lines transfected with pCMV6-A-GFP-MEG3 plus pCMV6-XL4- $\beta$-catenin and decreased in stable Hep3B cell lines transfected with pCMV6-A-GFP-MEG3. Next, we detected the cell proliferation. As shown in Fig. 11b, excessive MEG3 significantly decreased the growth of liver cancer cell Hep3B compared to the control cells $(P<0.01)$. However, HULC plus $\beta$-catenin did not significantly alter the growth of liver cancer cells $(P>0.05)$. Moreover, MEG3 overexpression significantly decreased the BrdU positive rate compared to the control cells $(22.46 \pm 5.18 \%$ versus 52.4 $\pm 10.71 \%, P=0.007949<0.01)$. However, MEG3 plus $\beta$ catenin did not significantly alter the BrdU positive rate of liver cancer cells $(56.43 \pm 13.27 \%$ versus $52.4 \pm 10.71 \%, P$ $=0.3793616>0.05$ ) (Fig. 11c). We further performed 
colony formation assay and observed a significant decrease in colony formation efficiency rate in excessive MEG3 $(13.04 \pm 3.76 \%$ versus $36.02 \pm 7.26 \%, P=0.004634$ $<0.01$ ). However, MEG3 plus $\beta$-catenin did not significantly alter the colony formation rate of liver cancer cells $\quad(39.12 \pm 10.6 \%$ versus $36.02 \pm 7.26 \%, \quad P=0.1985$ $>0.05$ ) (Fig. 11d). Furthermore, the three stable Hep3B cell lines were injected subcutaneously into athymic Balb/ $\mathrm{C}$ mice. As shown in Fig. 12a, when MEG3 was overexpressed, the average xenograft tumor weight decreased approximately 0.27 folds compared to the corresponding control group $(0.1267 \pm 0.039 \mathrm{~g}$ versus $0.4533 \pm 0.089 \mathrm{~g}$, $n=6, P=0.000347<0.01$ ). However, MEG3 plus $\beta$ catenin did not significantly alter the xenograft tumor weight $(0.4767 \pm 0.1138 \mathrm{~g}$ versus $0.4533 \pm 0.089 \mathrm{~g}, n=6$,
$P=0.251967>0.01)$. On the other hand, when MEG3 was overexpressed, the average xenograft tumor appearance time was significantly increased compared to the corresponding control group $(16.18 \pm 4.02$ days versus $9.4 \pm$ 2.37 days, $n=6, P=0.003787<0.01$ ). However, MEG3 plus $\beta$-catenin did not significantly alter the xenograft tumor appearance time $(9.08 \pm 1.62$ days versus $9.4 \pm$ 2.37 days, $n=6, P=0.41429>0.05$ ) (Fig. 12b). Moreover, the proliferation index (calculated as percentage of PCNA-positive cells) was significantly lower in MEG3 overexpressing xenograft tumors compared to the control group $(13.31 \pm 4.91 \%$ versus $41.33 \pm 7.88 \%, P=0.02939$ $<0.05)$. However, MEG3 plus $\beta$-catenin did not significantly alter the PCNA positive rate of liver cancer cells $(49.13 \pm 12.38 \%$ versus $41.33 \pm 7.88 \%, \quad P=0.237289$
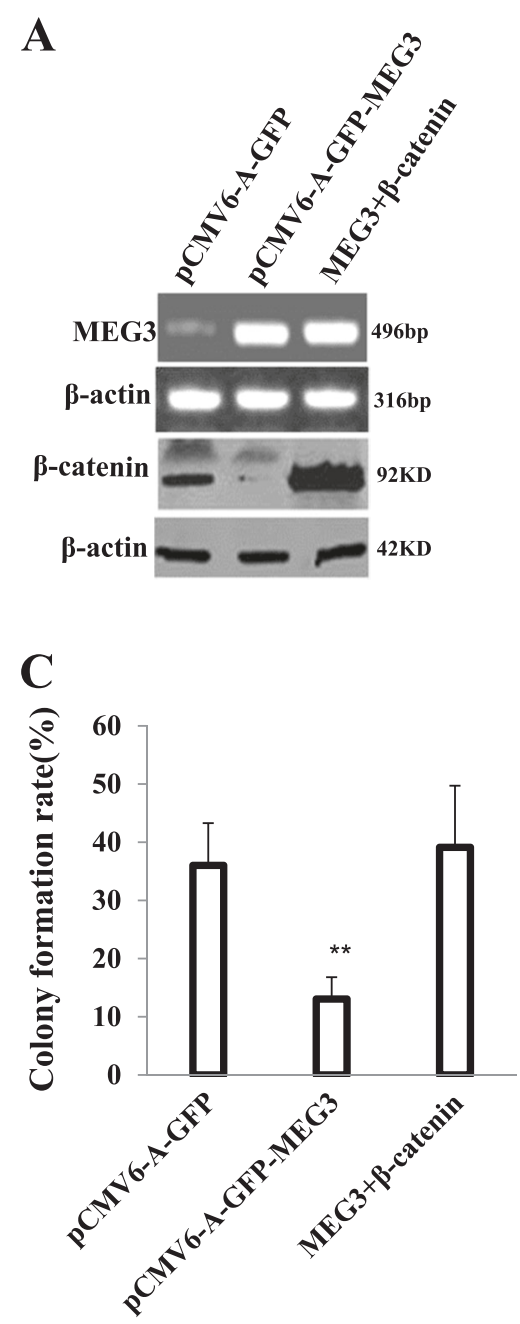

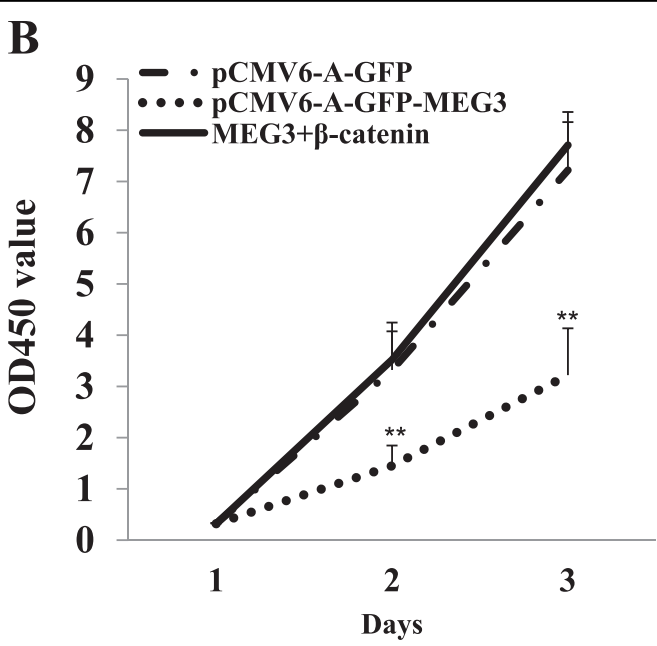

D

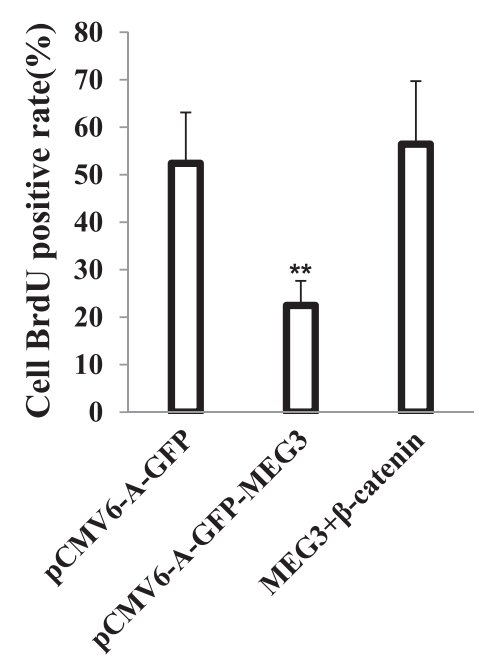

Fig. 11 Rescued $\beta$-catenin abrogated the MEG3 suppressor function in vitro. A Western blotting analysis with anti- $\beta$-catenin and PCR-PCR with MEG3 primers in the Hep3B cell lines transfected with pCMV6-A-GFP, pCMV6-A-GFP-MEG3, pCMV6-A-GFP-MEG3 plus pCMV6-XL5- $\beta$-catenin, respectively. $\beta$-actin served as an internal control. B Cells growth assay using CCK8. Each value was presented as mean \pm standard error of the mean (SEM). ${ }^{*}, P<0.01$. C Cell BrdU staining assay. Each value was presented as mean \pm standard error of the mean (SEM). ${ }^{* *}, P<0.01$. D Cells soft agar colony formation assay. Each value was presented as mean \pm standard error of the mean (SEM). ${ }^{*}, P<0.01$ 
$>0.05$ ) (Fig. 12c). Compared to the control, the expression of $\beta$-catenin and PKM2 is significant in the MEG3 overexpressing group (Fig. 12d). This suggested that MEG3 inhibited cell growth, colony formation ability, and cell growth in vivo. However, $\beta$-catenin overexpression abrogated the MEG3 action. Taken together, $\beta$-catenin determines the MEG3 suppressor function in liver cancer cells.

\section{Discussion}

It has been confirmed that MEG3 encodes an IncRNA which is suggested to function as a tumor suppressor and has been shown to involve in a variety of cancers. Our studies are now indicated to evaluate the effects of MEG3 in liver cancer cells. Our findings demonstrate that MEG3 inhibits the malignant progression of liver cancer cells in vitro and in vivo. Mechanistically, MEG3 promotes the expression and maturation of miR122 which targets PKM2. Therefore, MEG3 decreased the PKM2 expression and nuclear location dependent on miR122. Furthermore, MEG3 inhibited CyclinD1 and C-Myc via PKM2 in liver cancer cells. Strikingly, MEG3 promotes $\beta$-catenin degradation through ubiquitin-proteasome system dependent on PTEN. Moreover, MEG3 inhibits $\beta$-catenin activity through PKM2 reduction and PTEN increase. Furthermore, we found that excessive $\beta$-catenin rescued the effect of MEG3 in liver cancer (Fig. 13). To our knowledge, this is the first report demonstrating that lncRNA MEG3 suppresses liver cancer cells growth through $\beta$-catenin by activating PKM2 and PTEN.

To date, accumulating evidence indicates that MEG3 plays a critical role in cancer progression and metastasis.

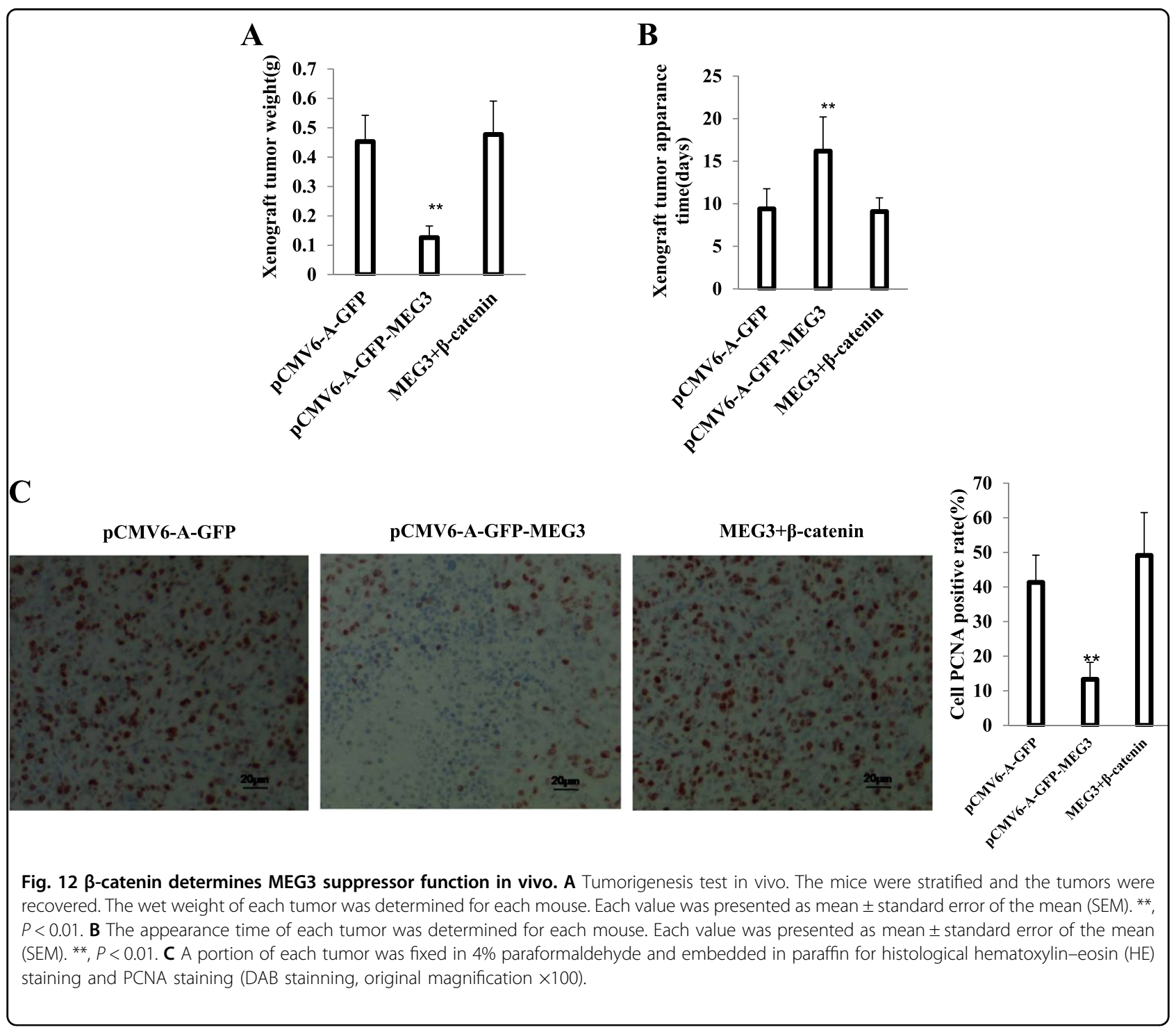




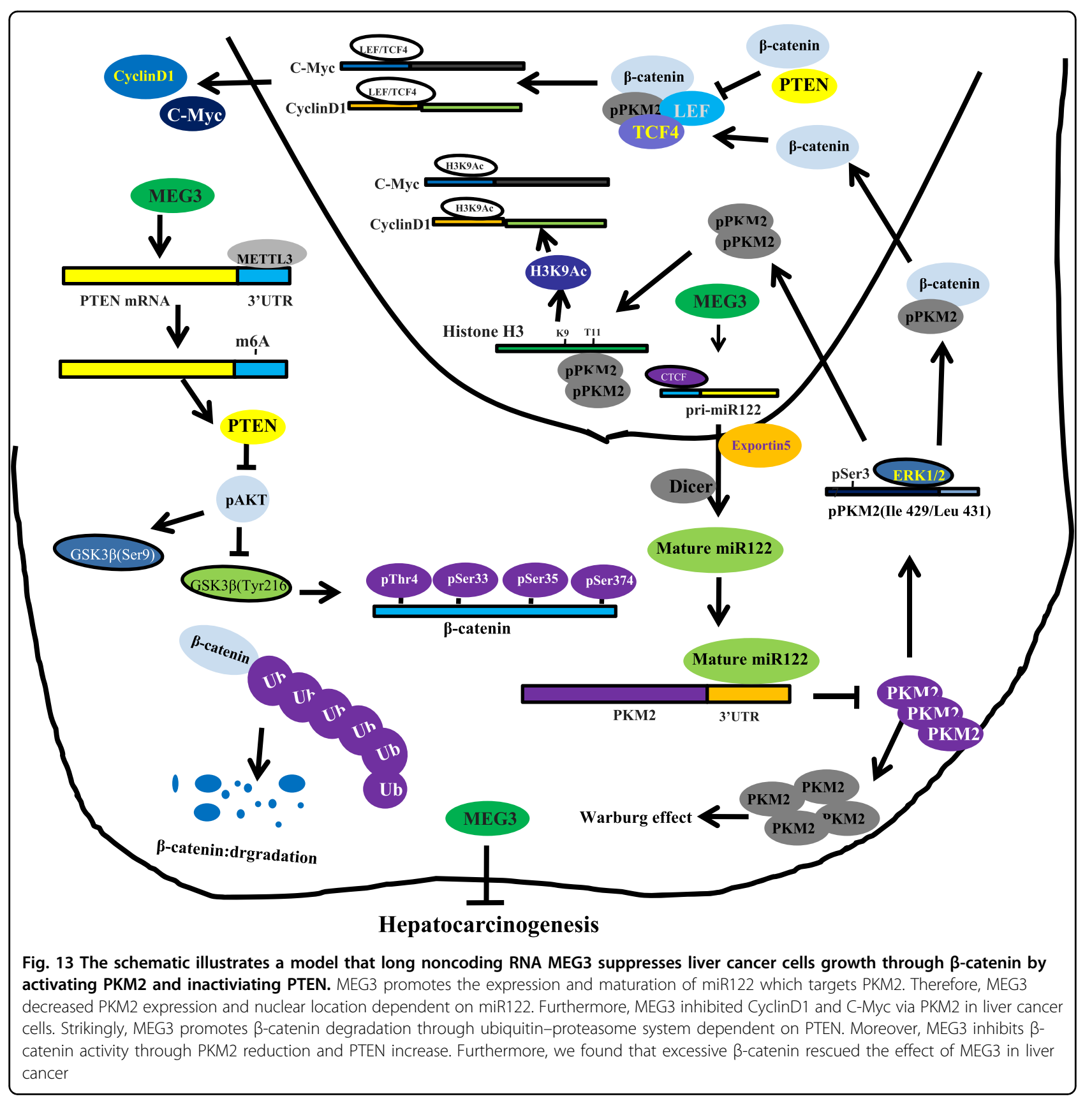

Previous studies suggested that MEG3 functioned through the activation of $\mathrm{p} 53$; however, the functional properties of MEG3 remain obscure and their relevance to human diseases is under continuous investigation ${ }^{43}$. Crosstalk between MEG3 and miR-1297 regulates the growth of testicular germ cell tumor through PTEN/ PI3K/AKT pathway ${ }^{44}$. MEG3 may be an underlying therapeutic target for LUAD functioning as ceRNAs for the regulation of miRNA-mRNA in lung adenocarcinoma ${ }^{45}$. In addition, MEG3 was decreased in primary endometrial stromal cells (ESCs) in response to TGF- $\beta 1$ stimulation $^{46}$.

Evidently, our results indicate that the involvement of MEG3 inhibition of liver cancer cell growth is supported by results from two parallel sets of experiments: ${ }^{1}$ MEG3 is downregulated and is postively associated with miR122, PTEN and negatively associated with PKM2, $\beta$-catenin expression in human liver cancer tissue ${ }^{2}$. MEG3 inhibits malignant progression of liver cancer cells in vitro and in vivo. Our observations demonstrated that MEG3 is 
crucial for the inhibition of cell growth and viability in liver cancer cells. According to the aforementioned findings, MEG3 is a tumor suppressor.

Of significance, our findings clearly showed that MEG3 promotes the expression and maturation of miR122 which targets PKM2 and inhibits the expression of PKM2. Studies indicate that alcoholic hepatitis accelerates early hepatobiliary cancer by increasing stemness and miR122mediated HIF- $1 \alpha$ activation ${ }^{47}$. Furthermore, miR122 is implicated as a regulator of physiological and pathophysiological processes in the liver. Ga12 overexpressed in hepatocellular carcinoma reduces microRNA-122 expression via HNF4 $\alpha$ inactivation, which causes c-Met induction $^{48}$. A quantitative mathematical model of HCVinduced miR-122 sequestration proposes that such miR122 inhibition by HCV RNA may result in global derepression of host miR-122 targets, providing an environment fertile for the long-term oncogenic potential of $\mathrm{HCV}^{49}$.

Accordingly, reduction in PKM2 may partly contribute to MEG3-mediated inhibition of liver cancer cell growth. Our findings in this study provide a novel evidence for an active role of PKM2 in MEG3-mediated inhibition of liver cancer cell growth. This assertion is based on several observations $^{1}$ : MEG3 decreased the PKM2 expression dependent on miR122 2 . MEG3 inhibits nuclear localization and function of PKM2 dependent on miR122 ${ }^{3}$. MEG3 inhibits the expression of cyclinD1 and C-Myc via PKM2. These findings are noteworthy, given that PKM2 is and functions as a key oncogene to mediate various biological processes including cell proliferation and differentiation. Moreover, PKM2 is associated with cancer differention ${ }^{50,51}$. Pyruvate kinase M2 activates mTORC1 by phosphorylating $\mathrm{AKT} 1 \mathrm{~S} 1^{52}$ and PKM2 promotes tumor angiogenesis by regulating HIF- $1 \alpha$ through NF- $\mathrm{KB}$ activation $^{53}$. In particular, cytosolic PKM2 stabilizes mutant EGFR protein expression through regulating HSP90-EGFR association ${ }^{54}$. PKM2 promotes stemness of breast cancer cell by through Wnt/ $\beta$-catenin pathway ${ }^{55}$. In addition, miR675 upregulates lncRNA H19 through activation of EGR1 in human liver cancer ${ }^{56}$. However, a study failed to observe PKM2-dependent transfer of phosphate from ATP directly to protein ${ }^{57}$. Furthermore, our findings indicated that MEG3 inhibited the expression of $\mathrm{C}$-myc, whereas $\mathrm{C}$-myc decides the reprogramming metabolism of cancer ${ }^{58}$.

Strikingly, we also demonstrated that MEG3 is closely associated with PTEN and $\beta$-catenin in liver cancer cells. This assertion is based on several observations ${ }^{1}$ : MEG3 increased the expression and phosphorylation of PTEN ${ }^{2}$. MEG3 promotes $\beta$-catenin degradation through ubiquitin-proteasome system dependent on PTEN $^{3}$. MEG3 inhibits $\beta$-catenin activity through PKM2 reduction and PTEN increase in liver cancer cells ${ }^{4}$. MEG3 inhibited cell growth, colony formation ability, and cell growth in vivo. However, $\beta$-catenin overexpression abrogated the MEG3 action. $\beta$-catenin determines MEG3 suppressor function in liver cancer cells.

It is well known that PTEN is a lipid phosphatase that converts phosphatidylinositol 3,4,5-phosphate (PIP3) to phosphatidylinositol 4,5-phosphate (PIP2) and plays a critical role in the regulation of tumor growth ${ }^{59,60}$. Notch promotes tumor metastasis in a prostate-specific PTENnull mouse model ${ }^{61}$. miR-18a promotes cell proliferation of esophageal squamous cell carcinoma cells by increasing cylin D1 via regulating PTEN-PI3K-AKT-mTOR signaling axis $^{62}$. Furthermore, PTEN is a key molecular controller of the PI3K signaling, and PI3K-PTEN dysregulation leads to mTOR-driven upregulation of the core clock gene BMAL1 in normal and malignant epithelial cells ${ }^{63}$. In particular, PTEN negatively regulates mTORC2 formation and signaling in grade IV glioma via Rictor hyperphosphorylation at Thr1135 and directs the mode of action of an mTORC1/2 inhibitor ${ }^{64}$. In addition, SOX7 co-regulates Wnt/ $\beta$-catenin signaling with Axin- $2^{65}$ and FAK promotes osteoblast progenitor cell proliferation and differentiation by enhancing Wnt signaling ${ }^{66}$. Moreover, FOXKs promote Wnt/ $\beta$-catenin signaling by translocating DVL into the nucleus ${ }^{67}$ and ECM1 regulates tumor metastasis and CSC-like property through stabilization of $\beta$-catenin ${ }^{68}$. A report shows that microRNA-153 promotes $\beta$-catenin activation in hepatocellular carcinoma through the suppression of WWOX ${ }^{69}$. Also, there is a regulation function between $\mathrm{Wnt} / \beta$-catenin signaling and PI3K/Akt survival pathway ${ }^{70}$.

\section{Conclusion}

The present study depicts a novel evidence for MEG3 that plays inhibiting tumorigenesis roles by downregulating PKM2 and $\beta$-catenin in liver cancer cells, which may have potential therapeutic significance. Alteration of the expression of IncRNAs MEG3 may also mediate changes at an epigenetic level to affect gene expression and contribute to inhibiting hepatocarcinogenesis. MEG3 overexpression in combination with blocking PKM2 and $\beta$-catenin might represent a promising treatment strategy targeting tumors. Our study for the first time demonstrated that MEG3 acts as a tumor suppressor by negatively regulating the activity of PKM2 and $\beta$-catenin in hepatocarcinogenesis and might serve as a prognostic biomarker and molecular therapeutic target.

\section{Acknowledgements}

This study was supported by grants from National Natural Science Fundation of China (NCSF No. 81572773) and National Natural Science Fundation of China (NCSF No. 81773158) and Key Specialty Construction Project of Pudong Health and Family Planning Commission of Shanghai (Grant No. PWZz201305). 


\section{Authors' contributions}

D.L. conceived the study and participated in the study design, performance, coordination, and manuscript writing. Q.Z., Z.L., J.X., Y.L., Q.M., C.W., Y.Y., X.X., X. L., H.P., X.G., T.L., and W.X. performed the research. All authors have read and approved the final manuscript.

\section{Author details}

'Research Center for Translational Medicine at Shanghai East Hospital, School of Life Science and Technology, Tongji University, 200092 Shanghai, China. ${ }^{2}$ Department of Hepatology, Shanghai East Hospital, Tongji University School of Medicine, 200120 Shanghai, China

\section{Conflict of interest}

The authors declare that they have no conflict of interest.

\section{Publisher's note}

Springer Nature remains neutral with regard to jurisdictional claims in published maps and institutional affiliations.

Received: 11 August 2017 Revised: 9 January 2018 Accepted: 11 January 2018

Published online: 15 February 2018

\section{References}

1. Zhang, J. et al. Long noncoding RNA MEG3 is downregulated in cervical cancer and affects cell proliferation and apoptosis by regulating miR-21. Cancer Biol. Ther. 17, 104-113 (2016).

2. Tian, Z. Z., Guo, X. J., Zhao, Y. M. \& Fang, Y. Fenofibrate inhibited pancreatic cancer cells proliferation via activation of p53 mediated by upregulation of LncRNA MEG3. Int J. Clin. Exp. Pathol. 8, 15138-15142 (2015).

3. Guo, Q., Qian, Z., Yan, D., Li, L. \& Huang, L. LncRNA-MEG3 inhibits cell proliferation of endometrial carcinoma by repressing Notch signaling. Biomed. Pharmacother. 82, 589-594 (2016).

4. Chang, L. et al. Armored long non-coding RNA MEG3 targeting EGFR based on recombinant MS2 bacteriophage virus-like particles against hepatocellular carcinoma. Oncotarget 7, 23988-24004 (2016).

5. Hu, D. et al. Fenofibrate inhibited pancreatic cancer cells proliferation via activation of p53 mediated by upregulation of LncRNA MEG3. Biochem. Biophys. Res. Commun. 471, 290-295 (2016).

6. Cao, X. et al. Associations between polymorphisms of long non-coding RNA MEG3 and risk of colorectal cancer in Chinese. Oncotarget 7, 19054-19059 (2016).

7. Li, J. et al. Epigenetic repression of long non-coding RNA MEG3 mediated by DNMT1 represses the p53 pathway in gliomas. Int. J. Oncol. 48, 723-733 (2016).

8. Pawar, K., Hanisch, C., Palma Vera, S. E., Einspanier, R. \& Sharbati, S. Down regulated IncRNA MEG3 eliminates mycobacteria in macrophages via autophagy. Sci. Rep. 6, 19416 (2016).

9. Luo, Z. et al. Regulation of the imprinted Dlk1-Dio3 locus by allele-specific enhancer activity. Genes Dev. 30, 92-101 (2016).

10. Gao, Y. \& Lu, X. Decreased expression of MEG3 contributes to retinoblastoma progression and affects retinoblastoma cell growth by regulating the activity of Wnt/ß-catenin pathway. Tumour Biol. 37, 1461-1469 (2016).

11. Liu, L. X. et al. The mechanism of adenosine-mediated activation of IncRNA MEG3 and its antitumor effects in human hepatoma cells. Int. J. Oncol. 48, 421-429 (2016).

12. Luo, G. et al. Non-coding RNA MEG3 inhibits cell proliferation and induces apoptosis in prostate cancer. Cell Physiol. Biochem. 237, 2209-2220 (2015).

13. Peng, W. et al. Long non-coding RNA MEG3 functions as a competing endogenous RNA to regulate gastric cancer progression. J. Exp. Clin. Cancer Res. 34, 79-82 (2015).

14. Mondal, T. et al. MEG3 long noncoding RNA regulates the TGF- $\beta$ pathway genes through formation of RNA-DNA triplex structures. Nat. Commun. $\mathbf{6}$, 7743 (2015).
15. Zhuang, W. et al. Upregulation of InCRNA MEG3 promotes osteogenic differentiation of mesenchymal stem cells from multiple myeloma patients by targeting BMP4 transcription. Stem Cells 33, 1985-1997 (2015).

16. Wu, C., Zhang, J., Cao, X., Yang, O. \& Xia, D. Effect of Mir-122 on human cholangiocarcinoma proliferation, invasion, and apoptosis through P53 expression. Med. Sci. Monit. 22, 2685-2690 (2016).

17. Wang, G. et al. Novel miR-122 delivery system based on MS2 virus like particle surface displaying cell-penetrating peptide TAT for hepatocellular carcinoma. Oncotarget 7, 59402-59416 (2016).

18. Simerzin, A. et al. The liver-specific microRNA-122*, the complementary strand of microRNA-122, acts as a tumor suppressor by modulating the p53/mouse double minute 2 homolog circuitry. Hepatology 64, 1623-1636 (2016).

19. Li, H. K. et al. DDX3 represses stemness by epigenetically modulating tumorsuppressive miRNAs in hepatocellular carcinoma. Sci. Rep. 6, 28637 (2016).

20. Pan, C. et al. MiR-122 reverses the doxorubicin-resistance in hepatocellular carcinoma cells through regulating the tumor metabolism. PLOS ONE 11, e0152090 (2016).

21. Valdmanis, P. N. et al. MiR-122 reverses the doxorubicin-resistance in hepatocellular carcinoma cells through regulating the tumor metabolism. Nat. Med. 22, 557-562 (2016).

22. Dong, G. et al. PKM2 and cancer: The function of PKM2 beyond glycolysis. Oncol. Lett. 11, 1980-1986 (2016)

23. Lu, W. et al. Up-regulation of PKM2 promote malignancy and related to adverse prognostic risk factor in human gallbladder cancer. Sci. Rep. 6, 26351 (2016).

24. Zhang, H. S. et al. Tanshinone IIA inhibits human esophageal cancer cell growth through miR-122-mediated PKM2 down-regulation. Arch. Biochem. Biophys. 98, 50-56 (2016).

25. Liang, J. et al. PKM2 dephosphorylation by Cdc25A promotes the Warburg effect and tumorigenesis. Nat. Commun. 7, 12431 (2016).

26. Park, S. H. et al. SIRT2-mediated deacetylation and tetramerization of pyruvate kinase directs glycolysis and tumor growth. Cancer Res. 76, 3802-3812 (2016).

27. Wu, M et al. Double mutant P53 (N3400/L344R) promotes hepatocarcinogenesis through upregulation of Pim1 mediated by PKM2 and LncRNA CUDR. Oncotarget 7, 66525-66539 (2016).

28. Liu, J. et al. Cdh1 inhibits WWP2-mediated ubiquitination of PTEN to suppress tumorigenesis in an APC-independent manner. Cell Discov. 2, 15044 (2016).

29. Bahena-Ocampo, I. et al. miR-10b expression in breast cancer stem cells supports self-renewal through negative PTEN regulation and sustained AKT activation. EMBO Rep. 17, 648-658 (2016).

30. Porter, S. N. et al. Pten cell autonomously modulates the hematopoietic stem cell response to inflammatory cytokines. Stem Cell Rep. 6, 806-814 (2016).

31. Jeyamohan, S., Moorthy, R. K., Kannan, M. K. \& Arockiam, A. J. Parthenolide induces apoptosis and autophagy through the suppression of PI3K/Akt signaling pathway in cervical cancer. Biotechnol. Lett. 38, 1251-1260 (2016).

32. Fortin, J., Bassi, C. \& Mak, T. W. PTEN enables the development of pre-B acute lymphoblastic leukemia. Nat. Med. 22, 339-340 (2016).

33. Ikenoue, T. et al. A novel mouse model of intrahepatic cholangiocarcinoma induced by liver-specific Kras activation and Pten deletion. Sci. Rep. 6, 23899 (2016).

34. Shojaee, S. et al. PTEN opposes negative selection and enables oncogenic transformation of pre-B cells. Nat. Med. 22, 379-387 (2016).

35. Ebbesen, S. H. et al. Pten loss promotes MAPK pathway dependency in HER2/ neu breast carcinomas. Proc. Natl Acad. Sci. USA 113, 3030-3035 (2016).

36. Li, Y. et al. MAF1 suppresses AKT-mTOR signaling and liver cancer through activation of PTEN transcription. Hepatology 63, 1928-1942 (2016).

37. Monga, S. P. $\beta$-Catenin signaling and roles in liver homeostasis, injury, and tumorigenesis. Gastroenterology 148, 1294-1310 (2015).

38. Yum, M. K. et al. AIMP2 controls intestinal stem cell compartments and tumorigenesis by modulating Wnt/B-catenin signaling. Cancer Res. 76, 4559-4568 (2016).

39. Zhuang, K. et al. Gastrin promotes the metastasis of gastric carcinoma through the $\beta$-catenin/TCF-4 pathway. Oncol. Rep. 36, 1369-1376 (2016).

40. Johnsen, J. I., Wickström, M. \& Baryawno, N. Wingless/ $\beta$-catenin signaling as a modulator of chemoresistance in cancer. Mol. Cell. Oncol. 3, e1131356 (2016).

41. Zhu, P. et al. Inc- $\beta$-Catm elicits EZH2-dependent $\beta$-catenin stabilization and sustains liver CSC self-renewal. Nat. Struct. Mol. Biol. 23, 631-639 (2016).

42. Wu, S. et al. MSK1-mediated $\beta$-catenin phosphorylation confers resistance to PI3K/mTOR inhibitors in glioblastoma. Mol. Cancer Ther. 15, 1656-1668 (2016). 
43. Zhu, J. et al. Long noncoding RNA MEG3 interacts with p53 protein and regulates partial p53 target genes in hepatoma cells. PLOS ONE 10, e0139790 (2015).

44. Yang, N. Q., Luo, X. J., Zhang, J., Wang, G. M. \& Guo, J. M. Crosstalk between Meg3 and miR-1297 regulates growth of testicular germ cell tumor through PTEN/PI3K/AKT pathway. Am. J. Transl. Res. 8, 1091-1099 (2016).

45. Li, D. S., Ainiwaer, J. L., Sheyhiding, l., Zhang, Z. \& Zhang, L. W. Identification of key long non-coding RNAs as competing endogenous RNAs for miRNAmRNA in lung adenocarcinoma. Eur. Rev. Med. Pharmacol. Sci. 20, 2285-2295 (2016).

46. Li, J., Cen, B., Chen, S. \& He, Y. MicroRNA-29b inhibits TGF- $\beta 1$-induced fibrosis via regulation of the TGF- $\beta 1 / \mathrm{Smad}$ pathway in primary human endometrial stromal cells. Mol. Med. Rep. 13, 4229-4237 (2016).

47. Ambade, A., Satishchandran, A. \& Szabo, G. Alcoholic hepatitis accelerates early hepatobiliary cancer by increasing stemness and miR-122-mediated HIF-1a activation. Sci. Rep. 6, 21340 (2016).

48. Yang, Y. M. et al. Ga12 overexpressed in hepatocellular carcinoma reduces microRNA-122 expression via HNF4a inactivation, which causes c-Met induction. Oncotarget 6, 19055-19069 (2015).

49. Luna, J. M. et al. Hepatitis C virus RNA functionally sequesters miR-122. Cell 160, 1099-1110 (2015)

50. Wei, L. et al. Oroxylin A activates PKM1/HNF4 alpha to induce hepatoma differentiation and block cancer progression. Cell Death Dis. 8, e2944 (2017).

51. Morfouace, M. et al. Control of glioma cell death and differentiation by PKM2Oct4 interaction. Cell Death Dis. 5, e1036 (2014).

52. He, C. L. et al. Pyruvate knase M2 activates mTORC1 by phosphorylating AKT1S1. Sci. Rep. 6, 21524 (2016).

53. Azoitei, N. et al. PKM2 promotes tumor angiogenesis by regulating HIF-1a through NF-KB activation. Mol. Cancer 15, 3 (2016).

54. Yang, Y. C. et al. Cytosolic PKM2 stabilizes mutant EGFR protein expression through regulating HSP90-EGFR association. Oncogene 35, 3387-3398 (2016).

55. Zhao, Z. et al. PKM2 promotes stemness of breast cancer cell by through Wnt/ B-catenin pathway. Tumor Biol. 37, 4223-4234 (2016)

56. $\mathrm{Li}, \mathrm{H}$. et al. miR675 upregulates long noncoding RNA H19 through activating EGR1 in human liver cancer. Oncotarget 6, 31958-31984 (2015).

57. Hosios, A. M., Fiske, B. P., Gui, D. Y. \& Vander Heiden, M. G. Lack of Evidence for PKM2 Protein Kinase Activity. Mol. Cell 59, 850-857 (2015).
58. Guo, X. et al. miR-181d and c-myc-mediated inhibition of CRY2 and FBXL3 reprograms metabolism in colorectal cancer. Cell Death Dis. 8, e2958 (2017).

59. Chen, Z. et al. Enzymatic analysis of PTEN ubiquitylation by WWP2 and NEDD4-1 E3 ligases. Biochemistry 55, 3658-3666 (2016).

60. Li, X. Y. et al. Triptolide restores autophagy to alleviate diabetic renal fibrosis through the miR-141-3p/PTEN/Akt/mTOR pathway. Mol. Ther. Nucleic Acids 9 , 48-56 (2017).

61. Kwon, O. J. et al. Notch promotes tumor metastasis in a prostate-specific Ptennull mouse model. J. Clin. Invest. 126, 2626-2641 (2016).

62. Zhang, W., Lei, C., Fan, J. \& Wang, J. miR-18a promotes cell proliferation of esophageal squamous cell carcinoma cells by increasing cylin D1 via regulating PTEN-PI3K-AKT-mTOR signaling axis. Biochem. Biophys. Res. Commun. 477, 144-149 (2016).

63. Matsumoto, C. S. et al. PI3K-PTEN dysregulation leads to mTOR-driven upregulation of the core clock gene BMAL1 in normal and malignant epithelial cells. Oncotarget 7, 42393-42407 (2016).

64. Bhattacharya, K. Maiti, S. \& Mandal, C. PTEN negatively regulates mTORC2 formation and signaling in grade IV glioma via Rictor hyperphosphorylation at Thr1135 and direct the mode of action of an mTORC1/2 inhibitor. Oncogenesis 5, e227 (2016)

65. Liu, H. et al. SOX7 co-regulates Wnt/B-catenin signaling with Axin-2: both expressed at low levels in breast cancer. Sci. Rep. 6, 26136 (2016).

66. Sun, C. et al. FAK promotes osteoblast progenitor cell proliferation and differentiation by enhancing Wnt signaling. J. Bone Miner. Res. 31, 2227-2238 (2016).

67. Wang, W. et al. FOXKs promote Wnt/B-catenin signaling by translocating DVL into the nucleus. Dev. Cell 32, 707-718 (2015)

68. Lee, K. M. et al. ECM1 regulates tumor metastasis and CSC-like property through stabilization of $\beta$-catenin. Oncogene 34, 6055-6065 (2015).

69. Hua, H. W., Jiang, F., Huang, Q., Liao, Z. \& Ding, G. MicroRNA-153 promotes Wnt/ $\beta$-catenin activation in hepatocellular carcinoma through suppression of WWOX. Oncotarget 6, 3840-3847 (2015).

70. Chandra, V. et al. Inhibitory effect of 2-(piperidinoethoxyphenyl)-3- (4-hydroxyphenyl)-2H-benzo(b)pyran (K-1) on human primary endometrial hyperplasial cells mediated via combined suppression of Wnt/ $\beta$-catenin signaling and PI3K/Akt survival pathway. Cell Death Dis. 5, e1380 (2014). 